\title{
INVENTÁRIO TAXONÔMICO DOS ANOSTOMÍDEOS (PISCES, ANOSTOMIDAE) DA BACIA DO RIO UATUMÃ-AM, BRASIL, COM DESCRIÇÃO DE DUAS ESPÉCIES NOVAS.
}

\author{
Geraldo M. dos SANTOS ${ }^{1}$, Michel JEGU ${ }^{2}$
}

RESUMO - O presente estudo trata do inventário, descrição e ilustração das espécies de anostomídeos da bacia do rio Uatumã. Ele foi desenvolvido com base na coleção de peixes do INPA, montada a partir de um intenso programa de coletas, na bacia do Uatumã, nas áreas de influência das usinas hidrelétricas de Balbina e Pitinga, ambas no estado do Amazonas. Para a maioria das espécies são feitos comentários sobre os caracteres diagnósticos, área de distribuição, biótopos preferenciais e principais variações do padrão de colorido entre adultos e jovens. As vinte e duas espécies identificadas pertencem a 8 gêneros, sendo Leporinus dominante, com 12 espécies, seguido de Laemolyta, Anostomus e Pseudanos, com duas e de Schizodon, Anostomoides, Synaptolaemus e Gnathodolus, com uma espécie cada. Dentre os peixes inventariados, duas espécies são consideradas novas e descritas (Leporinus uatumaensis sp.n e Leporinus pitingai sp.n.) A partir deste estudo, as espécies tiveram sua área de ocorrência ampliada, já que algumas delas só haviam sido assinaladas para a localidade-tipo.

Palavras chave: Ictiofauna, Amazônia, Anostomidae.

Taxonomic Inventory of Anostomids (Pisces, Anostomidae) of the Uatumã River Basin, Amazonas State, Brazil, with Description of Two New Species.

ABSTRACT - This study concerns in taxonomic survey on the anostomid species of the Uatuma River. It includes redescriptions and ilustrations of all species found at the area. The utilized material cames from an intensive fish survey program carried out at the Uatumã River drainage, in the area affected by the Balbina and Pitinga hydroelectric dams, boths in the Amazonas state. It is deposited at the icththyological collection of the Instituto Nacional de Pesquisas da Amazonia (INPA). Twenty two anostomid species were found in the Uatumã River drainage, belonging to eight genera, of which Leporinus were dominant, with twelve species, followed by Laemolyta, Anostomus, Anostomoides and Pseudanos (with two species) and Schizodon, Anostomoides, Synaptolaemus and Gnathodolus, with one species. Two species, Leporinus uatumaensis $\mathrm{n} . \mathrm{sp}$. and Leporinus pitingai $\mathrm{n} . \mathrm{sp}$. are considered new for science and here described. Diagnostic characters, distribution and habitat are cited; major ontogenetic changes in color patterns are also discussed. Several species had their distribution expanded.

Key words: Fishfauna, Amazon, Anostomidae.

\section{INTRODUÇÃO}

Os anostomídeos, popularmente denominados de aracus na região norte e de piaus nas demais regiões do Brasil, pertencem à família Anostomidae, um grupo de peixes da ordem Characiformes, restritos à América do Sul e com representantes em todas às bacias hidrográficas do
Brasil (GÉRY, 1961;1977).

Algumas espécies dos gêneros Leporinus, Schizodon e Rhytiodus alcançam até cerca de $400 \mathrm{~mm}$ de comprimento e um quilo de peso, tendo, portanto, uma elevada importância na pesca comercial. Outras espécies, como Synaptolaemus cingulatus e Anostomus ternetzi são de pequeno porte, até no máximo $80 \mathrm{~mm}$

1 Instituto Nacional de Pesquisas da Amazônia, Cx.P.478,Manaus,AM.

2 ORSTOM-DEC. 213, Rue La Fayette, Paris, 75480 França. 
e tem grande aceitação na aquariofilia. No todo, este grupo de peixes é formado por onze gêneros e cerca de 110 espécies, a maioria delas endêmicas da região amazônica.

Os anostomídeos da bacia amazônica são bem conhecidos do ponto de vista taxonômico e ecológico, principalmente através dos trabalhos de MYERS (1950), GÉRY (1960 a;b; 1972/ 73; 1977), GARAVELLO (1979), SANTOS $(1980 ; 1982)$ e SANTOS \& JÉGU (1987; 1989), entretanto, ainda existem grandes lacunas de conhecimento básico, pois extensas áreas da bacia amazônica ainda não foram sequer amostradas. Além disso, há fortes evidências de que diversas subbacias do sistema aquático amazônico encerram uma ictiofauna própria, com alto grau de endemismo.

A partir da criação, em 1976, de um curso de pós-graduação em biologia aquática, o INPA vem realizando inúmeras excursões para coleta de peixes e outros organismos aquáticos nas principais bacias hidrográficas da Amazônia. Este trabalho intensificou-se a partir da década de 80 , com a elaboração de programas de trabalho conjunto entre instituições de pesquisa, órgãos de fomento e agências de desenvolvimento e que visavam o diagnóstico ambiental de determinadas áreas. Através destes programas e também de coletas avulsas, o INPA montou coleções de peixes altamente representativas de alguns rios amazônicos, principalmente naqueles onde foram desenvolvidos inventários faunísticos como pré-requisito obrigatório para a construção de hidrelétricas, como no Tocantins, Jamari e Uatumã. Extensos trechos destes rios foram totalmente alterados por causa do represamento e isso levou a uma dizimação da maioria das espécies de anostomídeos que alí cororriam, principalmente nas áreas de corredeiras.

A maioria dos trabalhos taxonômicos, elaborados com base no material que constitui estas coleções encontra-se em forma de relatórios técnicos, contendo apenas uma lista de espécies. Trabalhos mais completos, contendo ilustrações ou chaves de identificação foram feitos sobre os peixes do baixo Tocantins (SANTOS $e t$ al., 1984), dos principais rios de Rondônia (SANTOS,1991) e do médio rio Amazonas, na região de Santarém (FERREIRA et al., no prelo). Outros trabalhos, considerando apenas determinados grupos de peixes, foram realizados no baixo rio Tocantins (PLOEG, 1986; JEGU \& SANTOS, 1988; SANTOS \& JEGU, 1989). Estudos sobre a alimentação e hábitos alimentares dos peixes do Uatumã foram desenvolvidos por LEITE (1987).

O objetivo do presente trabalho é o avanço do conhecimento sobre a ictiofauna dos rios amazônicos impactados por represamento. Ele trata do inventário dos anostomídeos coletados nos rios Uatumã e Pitinga, onde foram instaladas as hidrelétricas de Balbina e Pitinga, respectivamente, ambas no estado do Amazonas.

\section{Bacia do Rio Uatumã}

O rio Uatumã é um dos principais afluentes da margem esquerda do Amazonas, entre a foz do rio Negro e o 
Trombetas (Fig.1). Ele drena uma área de aproximadamente $70.600 \mathrm{Km}^{2}$, inserida em duas unidades morfo-estruturais distintas: 0 Escudo das Guianas, onde se situam o alto e médio cursos e a Planície Amazônica, nos cursos inferiores (RADAMBRASIL, 1976).

O perfil do Uatumã é de baixa declividade na maior parte de sua extensão, exceto nas zonas de corredeiras, das quais as mais importantes são Morena e Balbina, sendo esta última o local de instalação da Hidrelétrica Balbina. À jusante da cachoeira Morena, que é a última, a partir da nascente,o rio é largo, com margens baixas e é bastante influenciado pelo regime do rio Amazonas, que o represa na época da cheia, formando vários lagos marginais e extensas áreas de igapós. Acima da cachoeira Balbina o leito é bem delimitado, as áreas inundadas pelas enchentes são estreitas, sendo estas fortemente influenciadas pelas chuvas locais. Atualmente uma enorme área desse trecho, com aproximadamente $2.360 \mathrm{Km}^{2}$, constitui o reservatório da UHE Balbina, o qual tem um regime controlado pela operação das turbinas e portanto, com oscilações diárias do nível dágua.

A bacia do Uatumã localiza-se numa área dominada pela floresta tropical densa e é formada por numerosos igarapés, sendo o Pitinga seu principal afluente. Suas águas são típicas dos rios amazônicos de terra firme, com temperatura de 23 a $30^{\circ} \mathrm{C}, \mathrm{pH}$ 3,5 a 6 , condutividade 10 a 50 micromho/ $\mathrm{cm}$, oxigênio dissolvido 1,5 a $7 \mathrm{mg} / \mathrm{l}$, transparência 0,4 a $1,5 \mathrm{~m}$, material em suspensão 0,002 a $15 \mathrm{mg} / \mathrm{l}$ e cálcio em quantidades mínimas, até no máximo 0,7 miligramas por litro (RIBEIRO, $1985 \mathrm{a} ; \mathrm{b}$ ).

O regime hidrológico natural do Uatumã segue o mesmo padrão dos demais rios da Amazônia central, com um período de águas altas entre maio e junho e outro de águas baixas, de outubro a novembro. Sua vazão apresenta médias mensais entre 30 a $1370 \mathrm{~m} 3 / \mathrm{s}$ (ELETRONORTE (1976).

Todos os locais onde foram efetuadas as coletas de peixes estão situados nas áreas de influência das hidrelétricas de Pitinga e Balbina (Fig. 2), sendo que a maioria daqueles situados à montante destas usinas faz parte dos seus atuais reservatórios.

\section{MATERIAL E MÉTODOS}

A grande maioria dos peixes tratados no presente estudo foi coletada em dois locais e períodos distintos: no rio Uatumã, entre os anos de 1984 e 1987 e no rio Pitinga, entre 1994 e 1995. Estas coletas foram realizadas durante a execução do projeto de avaliação de impactos ambientais da UHE Balbina, do convênio INPA e ELETRONORTE e do projeto sobre pradarias de podostemácea, do convênio INPA e o instituto francês ORSTOM.

No rio Uatumã as coletas foram feitas antes da formação do atual reservatório da UHE Balbina e ao longo de cerca de $350 \mathrm{Km}$ deste rio, em diferentes biótopos, como leito, margens, boca de igarapés e lagos. No rio Pitinga, as coletas foram feitas em corredeiras próximas à Hidrelétrica de Pitinga, sendo uma delas situada à cerca 



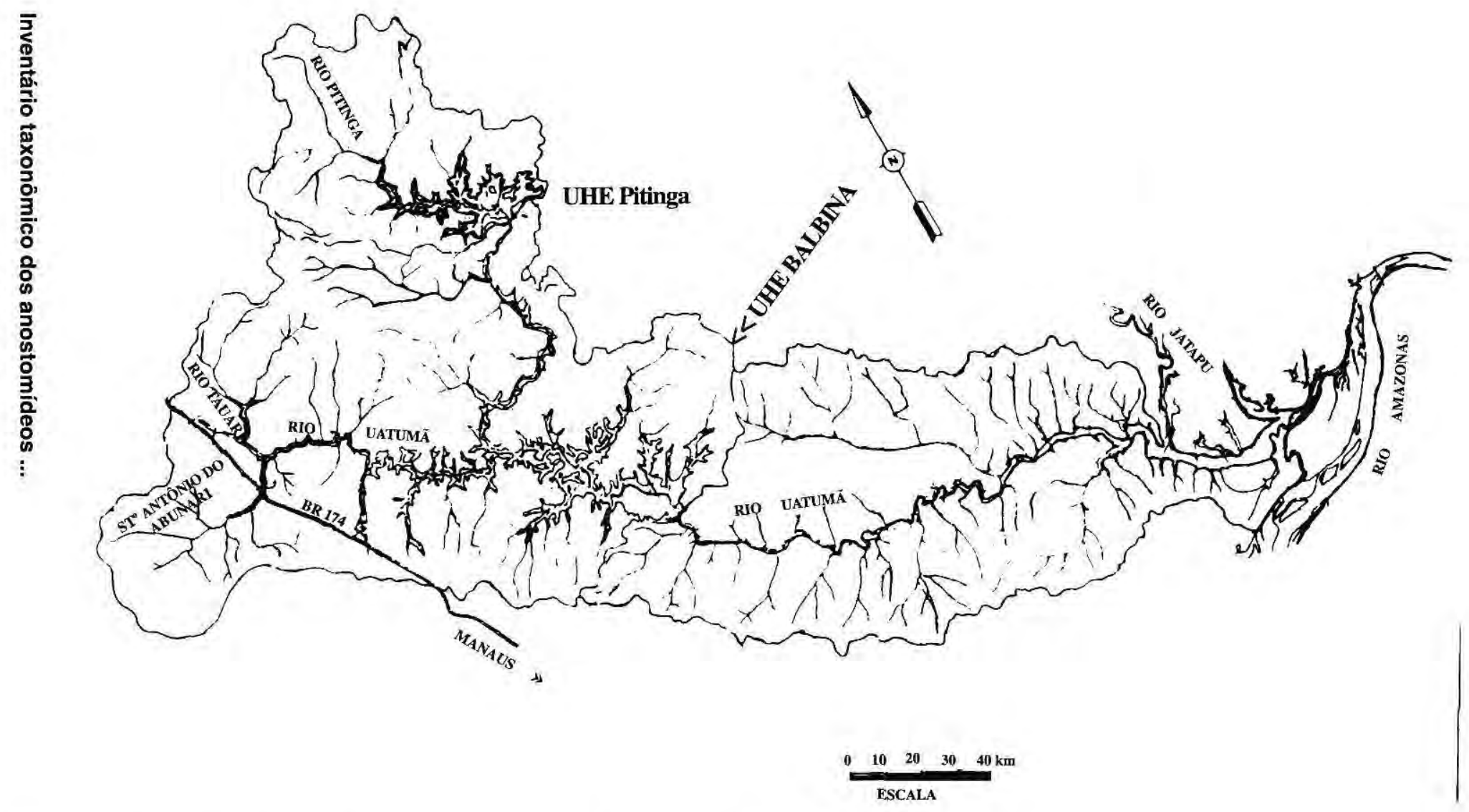


de $40 \mathrm{Km}$ à montante da barragem (Terceira Queda) e duas outras situadas à 8 e $20 \mathrm{Km}$ à jusante da barragem (40 Ilhas e Paredão, respectivamente).

As coletas foram feitas bimestralmente, com duração de 10 a 20 dias, abrangendo os períodos diurno e noturno. Os aparelhos de pesca utilizados foram malhadeira, tarrafa, rede de arrasto e ictiotóxico, sendo este último empregado apenas em poças isoladas ou em corredeiras. Representantes de todas as espécies coletadas, bem como todos os exemplares de espécies raras foram trazidas para o laboratório, onde se montou uma coleção de referência, a qual se constituiu de base para a elaboração do presente trabalho.

$\mathrm{O}$ material estudado encontra-se depositado na coleção central de peixes do Instituto Nacional de Pesquisas da Amazônia (INPA), sendo que tipos das espécies novas descritas foram também depositados no Museu de Zoologia da Universidade de São Paulo (MZUSP).

Os caracteres merísticos e morfométricos tomados foram aqueles normalmente citados para peixes de água doce, principalmente para os anostomídeos. As medidas e contagens empregadas foram feitas de acordo com os seguintes critérios:

Comprimento padrão: distância da ponta do focinho à extremidade posterior do corpo, ao nível da inserção dos raios caudais superiores;

Linha lateral: número total de escamas perfuradas ao longo do corpo;

Escamas acima da linha lateral: número de séries de escamas entre o ponto mais anterior da base da nadadeira dorsal e as escamas da linha lateral, sendo estas excluídas da contagem;

Escamas abaixo da linha lateral: número de séries de escamas entre o ponto mais anterior da base da nadadeira ventral e as escamas da linha lateral, sendo estas excluídas da contagem;

Escamas do pedúnculo caudal: menor número de série de escamas ao redor do pedúnculo caudal;

Escamas pré-dorsais: número de escamas da série mediana dorsal, entre a cabeça e a origem da nadadeira dorsal;

Escamas interdorsais: número de escamas da série mediana dorsal, entre as nadadeiras dorsal e adiposa;

Raios: número de raios das nadadeiras; os primeiros e últimos raios não ramificados são indicados pela letra "i" e os ramificados por algarismos arábicos. $\mathrm{O}$ dois últimos raios das nadadeiras dorsal e anal geralmente se encontram unidos pela base e foram considerados como sendo apenas um.

Dentes: Número de dentes bucais presentes em cada seção da arcada superior (pré-maxilar), seguido do número de dentes em cada seção da arcada inferior (mandíbula);

Altura do corpo: maior altura do corpo, na vertical entre a origem da nadadeira dorsal e a linha mediana do ventre;

Comprimento da cabeça: distância da ponta do focinho ao ponto mais distal do opérculo, excluída a membrana opercular;

Comprimento do pedúnculo caudal: distância entre a base posterior da nadadeira anal e a extremidade posterior do pedúnculo caudal, ao nível da linha lateral; 
Comprimento do focinho: distância da ponta do focinho até a margem anterior da órbita;

Diâmetro ocular: diâmetro do olho, medido horizontalmente em relação ao eixo do corpo;

Distância interorbital: menor distância entre as órbitas, tomada transversalmente sobre o topo da cabeça.

Os valores de proporcionalidade da altura do corpo, comprimento da cabeça e do pedúnculo caudal foram calculados em função do comprimento padrão e os valores relativos a comprimento do focinho, diâmetro ocular e distância interorbial, em função do comprimento da cabeça.

Os nomes vulgares das espécies são aqueles comumente empregados pelos pescadores ou moradores da região de estudo. Quando o nome era desconhecido, empregou-se os nomes atribuídos às mesmas espécies ou espécies semelhantes em outras regiões da Amazônia.

O padrão de colorido das espécies refere-se normalmente a exemplares adultos, preservados em alcool; no caso de exemplares vivos ou de jovens isso é salientado no item "comentários".

Todas as referências a comprimento do peixe, referem-se ao comprimento padrão. A ordem de apresentação das espécies no texto e nas ilustrações obedece à sequência em que estas aparecem na chave de identificação.

\section{Chave de Identificação das Espécies}

1. Boca parcial ou totalmente superior ....... 2

1 '.Boca terminal ou inferior 10

2. Boca totalmente superior; dentes delicados e alaranjados, lábios muito franjados

2 '. Boca parcialmente superior; dentes robustos e normalmente claros; lábios pouco franjados ....... 8 3. Apenas um dente exageradamente grande, em forma de foice, na mandíbula

Gnathodolus bidens (Fig. 3)

3'. Quatro dentes normalmente desenvolvidos de cada lado da mandíbula

4. Dentes com extremidades arredondadas ou pontudas em ambas as maxilas; faixas transversais escuras e alaranjadas, alternadamente, envolvendo todo o corpo ..... Synaptolaemus cingulatus (Fig. 4) 4'.Dentes bi ou tricuspidados em ambas as maxilas; manchas arredondadas ou faixas transversais restritas ao dorso 5

5. Listras longitudinais escuras e claras, alternadamente, sobre o corpo

Anostomus ternetzi (Fig. 5)

5. Manchas arredondadas ao longo da linha lateral; faixas, se presentes, restritas ao dorso .. 6 6. Linha lateral com 39 escamas

Anostomus plicatus (Fig. 6)

6'. Linha lateral com 42 a 45 escamas ........ 7

7. Linha lateral com 44 ou 45 escamas; corpo alongado, altura 4,7 a 5,2 vezes no comprimento padrão ................... Pseudanos gracilis (Fig. 7) 7. Linha lateral com 42 a 43 escamas; corpo alto, altura contida 3,2 a 3,6 vezes no comprimento padrão

Pseudanos trimaculatus (Fig. 8)

8. Dentes da mandíbula incisiviformes

Anostomoides laticeps (Fig, 9)

8 '. Dentes da mandíbula com extremidades planas 9

9. Corpo alongado, altura contida 4 a 4,8 vezes no comprimento padrão, uma listra escura ao longo da linha lateral ................. Laemolyta taeniata (Fig. 10) 9. Corpo alto, altura contida 3,7 a 4,2 vezes no comprimento, uma listra e duas a quatro faixas transversais escuras sobre o tronco

Laemolyta varia (Fig. 11)

10. Dentes largos, multicuspidados, em ambas as maxilas Schizodon fasciatus (Fig. 12)

10. Dentes incisiviformes ou truncados 11

11. Boca totalmente inferior; dentes pontudos, alinhados um ao lado do outro

Leporinus pachycheilus (Fig. 13)

11'. Boca terminal ou parcialmente inferior, dentes incisiviformes, em forma de escada 12

12. Várias faixas transversais amarelas e escuras, alternadamente, sobre o tronco 13 
12'. Padrão de coloração diverso do anterior ...... 14 13. Nadadeiras ventrais e dorsal uniformemente claras; linha lateral com 42 a 45 escamas Leporinus fasciatus (Fig. 14) 13'. Uma mancha escura na base das nadadeiras ventrais e dorsal; Linha lateral com 37 a 39 escamas ...... Leporinus desmotes (Figs. 15 e 16) 14. Coloração uniformemente marrom-clara; linha lateral com 41 a 42 escamas

Leporinus bruneus (Fig. 17)

14'. Uma listra horizontal na porção terminal do tronco ou de manchas arredondadas ao longo da linha lateral

15. Uma listra horizontal escura na porção terminal do tronco 16

15'. Ausência de listra horizontal sobre o tronco..

16. Linha lateral com 38 a 40 escamas; altura do corpo contida 3,2 a 3,7 vezes no comprimento padrão .

Leporinus agassizi (Figs. 18 e 19)

16. Linha lateral com 36 ou 37 escamas; altura do corpo contida 3,7 a 4,5 vezes no comprimento.

Leporinus uatumaensis sp.n. (Fig. 20)

17. Linha lateral com 33 a 35 escamas ......... 18

17'. Linha lateral com 38 a 44 escamas ....... 19

18. Numerosas manchas escuras sobre o tronco; maxila superior com três dentes de cada lado......

Leporinus megalepis (Figs. 21 e 22)

18 . Poucas ou nenhuma mancha sobre o tronco; maxila superior com quatro e eventualmente cinco dentes de cada lado

Leporinus granti (Figs. 23 e 24)

19. Corpo alongado, altura contida entre 4 e 5 vezes no comprimento padrão

19'. Corpo elevado, altura contida entre 3,1 e

3,7 vezes no comprimento padrão 21

20. Linha lateral com 38 ou 39 escamas, duas manchas escuras sobre a linha lateral

Leporinus aripuanaensis (Figs. 25 e 26)

20'. Linha lateral com 41 a 43 escamas, três manchas escuras sobre a linha lateral

Leporinus cylindriformes (Figs, 27 e 28)

21. Linha lateral com 38 a 39 escamas; normalmente três manchas arredondadas ou ovais sobre a linha lateral

Leporinus friderici (Figs. 29 e 30)

21'. Linha lateral com 41 a 44 escamas, normalmente sete manchas, algumas das quais alongadas verticalmente, sobre a linha lateral ...... Leporinus pitingai sp.n (Fig. 31)

\section{Espécies Inventariadas e Descrição de Espécies Novas}

\author{
Gnathodolus bidens Myers, 1927
}

(Tab.1, Fig.3)

Gnathodolus bidens Myers, 1950; Géry,1972/73; Santos \& Jegu, 1987. Nome comum: aracu, piau.

Material examinado: INPA 1164, 1 (113,5mm) Rio Uatumã, montante UHE Balbina, AM, 02 fevereiro/1985; INPA 10089, 1 (92mm), Rio Uatumã, jusante UHE Balbina, 24 outubro/1987.

Comentários: Esta espécie é a única do gênero Gnathodolus. Além do Uatumã, ela é citada apenas para a bacia do Orinoco, na Venezuela, sendo que apenas quatro exemplares desta espécie foram até agora citados na literatura (SANTOS \& JEGU, 1987). Recentemente oito exemplares foram coletados no rio Jamari, no canal de desvio da UHE Samuel, Rondônia (SANTOS,1991). Tanto pelo pequeno número de exemplares até agora coletados, como pelas exóticas características apresentadas, ela pode ser considerada como extremamente rara e só tem sido encontrada em áreas de pedrais.

Esta espécie apresenta nadadeiras uniformemente claras e o corpo cinza-amarelado, com duas a três manchas escuras arredondadas ao longo da linha lateral: a primeira, maior, ao nível da nadadeira dorsal; a segunda ao nível da nadadeira anal e a última, menos conspícua, na extremidade do pedúnculo caudal. Além destas, geralmente ocorrem cerca de sete manchas alongadas e inconspícuas na linha mediana do dorso, sendo mais destacadas as três da região predorsal. 
Synaptolaemus cingulatus Myers \& Fernandez-Yepes, in Myers,1950.

$$
\text { (Tab.1, Fig.4) }
$$

Synaptolaemus cingulatus Géry, 1972/73; Santos \& Jegu, 1987.

Nome comum: aracu rajado.

Material examinado: INPA 10047, 6 (46$104 \mathrm{~mm}$ ), Rio Uatumã, poças remanescentes à jusante UHE Balbina, 04 outubro/1987; INPA 10048, 6 (29$70 \mathrm{~mm}$ ), Rio Uatumã, poças jusante UHE Balbina 22 outubro/1987; INPA 10051, 2 (63-74mm), Rio Uatumã, jusante UHE Balbina, 02 outubro/1987; INPA 10052, 1 (84mm), Rio Uatumã, Cachoeira Morena, jusante UHE Balbina, 02 outubro/1987; INPA 10053,2 (24-45mm), Rio Uatumã, jusante UHE Balbina, 28 outubro/1987; INPA 10054, 1 (94mm), Rio Uatumã, jusante UHE Balbina, 24 outubro/1987; INPA 10055, 1 (37 mm), Rio Uatumã, Cachoeira Morena, 08 outubro/1987.

Comentários: Synaptolaemus cingulatus é assinalada para os rios Orinoco, Xingu, Trombetas e Aripuanã e tem sido capturada apenas em áreas de corredeiras, com fundo pedregoso (SANTOS \& JEGU, 1987). A dieta desta espécie é constituída basicamente de esponjas, algas, detritos e larvas de insetos, sendo que a presença constante de areia junto ao conteúdo estomacal indica que ela se alimenta no fundo (SANTOS \& ROSA, no prelo).Trata-se, portanto, de um fato curioso, já que esta espécie possui a boca totalmente voltada para cima. Por causa de seu exótico padrão de colorido, é uma espécie de grande importância na aquariofilia.

\section{Anostomus ternetzi Fernandez- Yepez, 1949}

(Tab.1; Fig.5)

Anostomus ternetzi Myers,1950; Géry,1960a;b,1961;1972/73; Winterbottom, 1980.

Nome comum: aracu miúdo, aracu rajado.
Material examinado: INPA 10000, 3 (24$47 \mathrm{~mm}$ ), Rio Uatumã, Cachoeira Morena, jusante UHE Balbina, 03 outubro/1987; INPA 10001, 1 (69,3mm), Rio Uatumã, jusante UHE Balbina, 24 outubro/1987; INPA 10002, $2(50,5-56,7 \mathrm{~mm})$, Rio Uatumã, próximo igarapé Arraia, acima UHE Balbina, 21 abril/1985; INPA 10003, 2 (37-45mm), Rio Uatumã, Cachoeira Morena, 14 outubro/1987; INPA $10004,4(36,1-40,3 \mathrm{~mm})$, Rio Uatumã, Cachoeira Morena, 03 outubro/1987; INPA 10005, 12 (41,5-70mm), Rio Uatumã, jusante UHE Balbina, 28 outubro/1987; INPA 10006, 5 (46,3$70,7 \mathrm{~mm})$, Rio Uatumã, jusante UHE Balbina, 22 outubro/1987; INPA 10032, 1 (40,2 mm) Rio Uatumã, jusante UHE Balbina, 02 outubro/1987; INPA 10033, 2 (56,7-59,1 mm), Rio Uatumã, jusante UHE Balbina, 26 outubro/1987.

Comentários: Anostomus ternetzi é citada para os rios Tapajós, Xingu, Negro e Tocantins (WINTERBOTTOM, 1980; SANTOS \& JEGU, 1989). Os dados de captura indicam que ela ocorre apenas nas áreas de corredeiras, com fundo pedregoso. Sua dieta é constituída basicamente de esponjas, plantas aquáticas, algas, detritos e larvas de insetos (SANTOS \& ROSA no prelo). Ela é uma das ' espécies de anostomídeos mais citadas nos compêndios de aquariofilia.

\section{Anostomus plicatus}

Eigenmann,1912

(Tab.1; Fig.6)

Anostomus plicatus Winterbottom, 1980.

Nome comum: aracu miúdo.

Material examinado: INPA 10088, 1 $(65 \mathrm{~mm})$, Rio Uatumã, pé da barragem UHE Balbina, 24 outubro/87.

Comentários: Anostomus plicatus é citada apenas para o território das Guianas, nos rios Essequibo e Rupununi (WINTERBOTTOM, 1980). No rio Uatumã foi coletado apenas um único exemplar, o que evidencia tratar-se de uma espécie incomum. 


\section{Pseudanos gracilis (Kner,1859)}

(Tab.1; Fig.7)

Schizodon gracilis Kner, 1859; Anostomus gracilis Géry,1977; Pseudanos gracilis Winterbottom, 1980; Santos, 1991; Ferreira,1992.

Nome comum: aracu, piau

Material examinado: INPA 10022, 1 (162,5mm), Rio Uatumã, Santa Luzia, acima UHE Balbina, 29 julho/1987; INPA 10023, 1 (128,5mm) Rio Uatumã, Igrapé Caititu, acima cachoeira Balbina, 19 de outubro/1983; INPA 10024, 1 (141,2mm), Rio Uatumã, Igarapé Arraia, acima cachoeira Balbina, janeiro/1985; INPA 10025, 2 (147-149,3mm), Rio Uatumã, Igarapé Santa Luzia, setembro/1985.

Comentários: Esta espécie é citada para várias bacias da Amazônia, incluindo os rios Negro, Guaporé, Trombetas e Jamari. Os exemplares analisados possuem quatro raios branquiostégios, ao contrário de três, conforme citado por WINTERBOTOM (1980) e em nenhum exemplar foi observada a faixa longitudinal ao longo do meio do corpo, como geralmente é atribuída a esta espécie. Praticamente todos os exemplares coletados na bacia do Uatumã são provenientes de igarapés, evidenciando ser este seu biótopo preferencial.

\section{Pseudanos trimaculatus (Kner,1859)}

$$
\text { (Tab.1; Fig.8) }
$$

Schizodon trimaculatus Kner,1859; Anostomus trimaculatus Myers,1950; Géry,1961, Knoppel,1970.

Nome comum: aracu, piau.

Material examinado: INPA 3204, 1 (148mm), Rio Pitinga, estação Bom Futuro, 17 outubro/1989; INPA 3214, 1 (172mm), Rio Pitinga, montante UHE Pitinga, 14 outubro/1985; INPA 10030, 3 (123,8-127,9mm), Rio Uatumã, Igarapé do Arraia, acima cachoeira Balbina, janeiro/1985; INPA 10031, 2 (125,6-127,3mm), Rio Uatumã, Igarapé do
Arraia, 15 abril/1983.

Comentários: Pseudanos trimaculatus é citada para as bacias da Amazônia, Paraná-Pagaruai e Guianas, entretanto há uma grande variação de seus caracteres, sendo provável que o complexo $P$. trimaculatus seja formado por diferentes populações ou mesmo espécies distintas. O número de manchas escuras ao longo da linha lateral desta espécie é muito variável, havendo citações de duas a quatro. Nos exemplares analisados apenas duas manchas são bem visíveis, sendo uma no meio do corpo e outra no pedúnculo caudal;a terceira mancha, citada para a região humeral, é apenas vestigial e a quarta, citada para o nível da origem da anal, encontra-se ausente.

Em exemplares jovens, com até cerca de $70 \mathrm{~mm}$ de comprimento padrão ocorrem cerca de 14 faixas transversais escuras e estreitas na região dorsal, sendo 5 a 6 prédorsais, 2 na base da dorsal, cerca de 6 na região pós-dorsal e 2 a 3 na região pós-adiposa, sendo que estas faixas não ultrapassam o nível da linha lateral.

Anostomoides laticeps (Eigenmann,1912)

$$
\text { (Tab.1; Fig.9) }
$$

Schizodontopsis laticeps Eigenmann,1912; Anostomoides laticeps Myers, 1950; Géry,1977; Santos et al.,1984; Santos,1991; Ferreira, 1992.

Nome comum: aracu-de-pedra.

Material examinado: INPA 3210, $1(230 \mathrm{~mm})$, Rio Pitinga, pé da represa da UHE Pítinga ou Paranapanema, AM., 11 oumbro89; INPA 10090, 3 (200-239mm), Rio Uatumã, Cachoeira Miriti, abaixo cachoeira Balbina, fevereiro/1985; INPA 10091, I (199mm), Rio Uatumã, Nazaré, fevereiro/1985; INPA 10092, 1 (202mm), Rio Uatumã, UHE Balbina, novembro/1984; 
INPA 10093, 1 (197mm), Rio Uaturnã, Igarapé Santa Luzia, acima cachoeira Balbina, fevereiro/1985; INPA 10094, 7 (194-250mm), Rio Uatumã, jusante UHE Balbina, julho/1987; INPA 10095, 1 (172mm), Rio Uatumã, Igarapé do Arraia, acima cachoeira Balbina, $15 \mathrm{abri1} / 1983$.

Comentários: Anostomoides laticeps é citada para os rios Essequibo, Tocantins, Jamari, Trombetas e Negro. Ela forma cardumes mistos com outras espécies de Characiformes e empreende migrações em determinadas épocas do ano. No baixo rio Negro, durante um ciclo anual completo, pudemos observar que todos os exemplares desta espécie se encontravam em repouso gonadal; isso sugere que a sua área de desova se localiza nos cursos superiores. Na bacia do Uatumã foram observados cardumes de peixes em repouso gonadal e muito gordos concentrados no sopé da barragem de Pitinga, tentanto ultrapassála, em direção à montante; isso indica que ela empreende também migração não reprodutiva.

\section{Laemolyta taeniata (Kner,1859)}

$$
\text { (Tab, 1; Fig.10) }
$$

Schizodon taeniatus Kner,1859; Laemolyta taeniata Myers,1950; Géry,1972/73, Santos, 1991.

Nome comum: Aracu caneta.

Material examinado: INPA 10009, 1 (221), Rio Uatumã, Igarapé do Arraia, acima cachoeira Balbina, 13 outubro/1983; INPA 10010, 1 (173mm), Rio Pitinga, Igarapé Água Branca, 17 outubro/1983; INPA 10011, 1 (218mm) Rio Uatumã, Poço do Nazaré, 19 abril/1983; INPA 10012, 6 (145-192mm), Rio Uatumã, Samaúma, próximo rio Amazonas, setembro/1985; INPA 10015, 1 (174mm), Rio Uatumã, Igarapé Arraia, acima cachoeira Balbina, janeiro/1985; INPA 10016, 2 (210-212mm), Rio Uatumã, Igarapé Arraia, fevereiro/1985; INPA 10017, 1 (229mm), Rio Uatumã, novembro/1984; INPA 10026, 2 (166-236), Rio Uatumä, Igarapé Abonari, acima cachoeira Balbina, 18 fevereiro/1983; INPA 10027, 1 (191mm), Rio Uatumã, $5 \mathrm{Km}$ acima UHE Balbina, 21 fevereiro/1983; INPA 10028, 1 (229mm), Rio Uatumã, UHE Balbina, setembro/1985; INPA 10029, 4 (211- 223mm), Rio Uatumā, Cachoeira Miriti, abaixo cachoeira Balbina, fevereiro/ 1985.

Comentários: Laemolyta taeniata distribui-se amplamente em toda a bacia amazônica e é comumente encontrada tanto em lagos como em leito de rios. Em Junho/94 foram observados grandes cardumes desta espécie no sopé da barragem da hidrelétrica Pitinga, tentanto transpô-la, em direção à montante, juntamente com cardumes de Leporinus fasciatus e $L$ agassizi; isso indica que ela é uma espécie migradora.

\section{Laemolyta varia (Garman,1890)} (Tab, 1; Fig.11)

Anostomus varius Garman,1890; Laemolyta varia Myers,1950; Santos,1982.

Nome comum: aracu caneta.

Material examinado: INPA 10007, 1 (232,2mm), Rio Uatumã, Igarapé Miriti, abaixo cachoeira Balbina, fevereiro/1985; INPA 10008, 3 (168,7-189mm), Rio Uatumã, Igarapé Miriti, fevereiro/1985; INPA 10013, 2 (216,7-259,3mm), Rio Uatumã, Lago Samaúma, próximo rio Amazonas, 13 agosto/1987; INPA 10014, 3 (226,5-229,1mm), Rio Uatumã, Lago Samaúma, próximo rio Amazonas, setembro/1985; INPA 10018, 1 (185mm), Rio Uatumã, Cachoeira Morena, jusante UHE Balbina, 18 novembro/1994; INPA 10019, 1 (251mm), Rio Pitinga, Cachoeira Travessão, abaixo UHE Pitinga, 12 janeiro/1995; INPA 10020, 1 (175mm), Rio Pitinga, 12 janeiro/1995; INPA 10021, $1(212 \mathrm{~mm})$ Rio Pitinga, Cachoeira Travessão, 12 janeiro/1995.

Comentários: Laemolyta varia apresenta uma ampla distribuição pela bacia amazônica, entretanto é mais comum em lagos de várzea. Por ser uma espécie que forma cardumes e ser muito abundante em determinadas épocas, ela normalmente faz parte do pescado comercializado na região.

\section{Schizodon fasciatus Agassiz, 1829}

$$
\text { (Tab.1; Fig.12) }
$$

Schizodon fasciatus Eigenmann,1912; Géry,1977; Santos, 1980. 
Nome comum: aracu comum, aracu malhado

Material examinado: INPA 10056, 1 (253mm), Rio Pitinga, Cachoeira 40 Ilhas, abaixo UHE Pitinga, 9 dezembro/1993; INPA 10057, 1 (260 mm) Rio Pitinga, Cachoeira 40 Ithas, 02 junho/1994; INPA 10058, I (285mm), Rio Pitinga, Cachoeira 40 Ithas, 02 junho/ 1994; INPA 10059, 1 (160 mm), Rio Pitinga, Cachoeira 40 llhas, 09 dezembro/1993; INPA 10060, 1 (265mm), Rio Pitinga, Cachoeira 40 Ilhas, 02 junho/1994; INPA 10061, 1 (262mm) Rio Uatumã, Samaúma, abaixo cachoeira Balbina, setembro/1985; INPA 10062, 1 (270mm), Rio Uatumã, Samaúma, fevereiro/1985; INPA 10063, $2(289-313 \mathrm{~mm})$, Rio Uatumã, Samaúma, setembro/1985; INPA 10064, 1 (243mm), Rio Pitinga, Cachoeira 40 llhas, 02 junho/1994.

Comentários: Schizodon fasciatus tem uma ampla área de distribuição e é uma das espécies mais comuns em toda a Amazônia. Devido à sua abundância e porte, é também uma das espécies de anostomídeos mais destacada na pesca comercial da região. Ela tem uma forte preferência por rios e lagos de várzea, onde se alimenta basicamente de raizes e folhas de capins flutuantes (SANTOS, 1981). No rio Uatumã, foram encontrados cardumes desta espécie aglomerados no sopé da barragem, tentando atingir o curso à montante. Foi observado que esta espécie é muito comum no reservatório da UHE Samuel, sendo atualmente uma das espécies dominantes e sobre a qual vem sendo exercido um grande esforço de pesca, tanto a comercial como a de subsistência (SANTOS, 1995).

\section{Leporinus pachycheilus Britski, 1976}

$$
\text { (Tab.1; Fig.13) }
$$

Leporinus pachycheilus Garavello, 1979; Santos \& Jegu, 1989.

Nome comum: aracu charuto.

Material examinado: INPA 10128, 1 (201 mm), Rio Pitinga, Cachoeira $3^{n}$ queda, montante UHE Pitinga, 05 fevereiro/1994; INPA 10129, 2 (185-200mm), Rio Pitinga, Cachoeira 40 Ilhas, jusante UHE Pitinga, 07 abri1/1994; INPA 10130 , 2 (225-250mm), Rio Pitinga, Cachoeira $3^{\mathrm{a}}$ queda, montante UHE Pitinga, 14 agosto/1994; INPA 10131, 1 (208mm), Rio Pitinga, Cachoeira 40 Ihas, jusante UHE Pitinga, 12 janeiro/95.

Comentários: Leporinus pachycheilus só foi citada até o momento para as bacias do Madeira (BRITSKY, 1976; SANTOS, 1991) e Tocantins (SANTOS et al., 1984). Os exemplares citados para a bacia do Trombetas (FERREIRA,1992) provavelmente pertencem a uma espécie semelhante, ainda não descrita (obs. pessoal). Os dados de coleta evidenciam que ela só ocorre em em áreas de corredeiras, com fundo pedregoso e se alimenta basicamente de podostemáceas, uma planta aquática e rupestre denominada vulgarmente de alface-d'água.

O colorido desta espécie é bastante variável, podendo aparecer faixas longitudinais ao longo do corpo ou de várias manchas ovais. Em vida, todos os exemplares apresentam uma série de 4 a 5 pontos vermelhos no centro das primeiras escamas situadas logo abaixo da linha lateral e um ponto vermelho na cava que abriga a porção lateral dos lábios.

\section{Leporinus fasciatus (Bloch,1794)}

$$
\text { (Tab.1; Fig.14) }
$$

Salmo fasciatus Bloch,1794; Leporinus fasciatus Eigenmann,1912; Géry,1977; Garavello,1979.

Nome comum: aracu flamengo.

Material examinado: INPA 2743, 5 (229264mm), Rio Uatumã, setembro/1985; INPA 2746, 1 (138mm), Rio Uatumã, Sumaúma, jusante cachoeira Balbina, setembro/1985; INPA 10034, 1 (151mm), Rio Uatumã, Poço do Nazaré, 19 abril/1983; INPA 10035, 9 (183-232mm), Rio Uatumã, Igarapé Nazaré, acima UHE Balbina, 15 outubro/1983; INPA 10036, 1 (79mm), Rio Uatumâ, Cachoeira Morena, 14 outubro/1987.

Comentários: Leporinus fasciatus 
tem uma ampla área de distribuição, abrangendo rios das Guianas e toda a Amazônia, sendo também comum tanto em lagos de várzea, como igapós e corredeiras. Ela é uma das espécies de anostomídeos que alcança maior porte, até cerca de de $350 \mathrm{~mm}$ de comprimento e um quilo de peso, tendo portanto grande importância na pesca comercial. Ela é uma espécie migradora. Em junho e outubro/94 grandes cardumes desta espécie, juntamente com Leporinus agassizi e Laemolyta taeniata, encontravam-se aglomerados no sopé da barragem da hidrelétrica de Pitinga, tentanto ultrapassá-la em diração à montante. Sua dieta é composta basicamente de larvas de insetos e a desova ocorre apenas uma vez por ano, no início da enchente.

O colorido desta espécie, em vivo, consiste de faixas escuras sobre um fundo amarelo-ouro, sendo a parte inferior da cabeça e a região opercular alaranjadas.

\section{Leporinus desmotes Fowler,1914}

(Tab.1; Fig.15 e 16)

Leporinus desmotes Géry,1977; Garavello,1979; Santos \& Jegu, 1989

Nome comum: aracu flamengo.

Material examinado: INPA 10065, 1 $(88 \mathrm{~mm})$, Rio Uatumã, jusante UHE Balbina, 24 outubro/1987; INPA 10066, 16 (75-137mm), Rio Uatumã, jusante UHE Balbina, 26 outubro/1987; INPA 10134, 4 (23-26mm), Rio Uatumã, Cachoeira Morena, abaixo UHE Balbina, 07 outubro/1987.

Comentários: A localidade-tipo desta espécie é o rio Rupununi, Guiana Inglesa, mas tem sido citada para a Venezuela e vários rios da Amazônia brasileira, como Tocantins (SANTOS \& JEGU, 1989), Jamari e Machado (SANTOS, 1991). Esta espécie apresenta preferência por áreas de corredeiras, em pedrais e os indivíduos são normalmente capturados em pequeno número, indicando que ela não forma cardumes.

Leporinus desmotes tem uma dentição típica, consistindo-se de um par sinfisial muito desenvolvido e comprimido lateralmente, o que levou GÉRY (1977) a considerá-la como um sub-gênero monotípico de Leporinus (L. myocharax).

As principais diferenças no padrão de colorido entre adutos e jovens, com até cerca de $25 \mathrm{~mm}$ de comprimento (Fig.16) é que nestes, as duas primeiras manchas sobre a cabeça e a mancha ao nível da nadadeira dorsal com a imediatamente seguinte são coalescentes; além disso, ocorre uma mancha puntiforme e escura na extremidade do pedúnculo caudal e uma faixa escura na lateral do focinho.

Leporinus brunneus Myers, 1950 (Tab.1; Fig.17)

Leporinus brunneus Garavello,1979; Santos, 1991.

Nome comum: aracu branco

Material examinado: INPA 5025, 1 $(280 \mathrm{~mm})$, Rio Uatumã, Igarapé Arraia, acima cachoeira Balbina, 15 abril/1983; INPA 10067, 1 (203mm), Rio Uatumã, 15 outubro/1983; INPA 10068, 1 (147mm), Rio Uatumã, Igarapé Arraia, 15 abril/1983; INPA 10069, 3 (210-260mm), Rio Uatumã, novembro/1984; INPA 10083, 1 (256 mm), Rio Uatumã, Igarapé Tucurutuba, 01 março/1983; INPA 10084, $1(265 \mathrm{~mm})$, Rio Uatumã, Igarapé Arraia, maio/1985; INPA 10085, 2 (306-323mm), Rio Uatumã, Igarapé Barreto, acima cachoeira Balbina, 27 abril/1983.

Comentários: Leporinus brunneus diferencia-se das demais espécies de anostomídeos do Uatumã pelo colorido do corpo, uniformemente claro. Esta espécie tem sido assinalada para os rios Negro, Tapajós, Curuá-Una, Aripuanã e Orinoco e os dados de coleta sugerem 
que ela só ocorre nos rios periféricos da bacia amazônica, sobretudo em pequenos igarapés.

\section{Leporinus agassizi Steindachner,} 1876 (Tab.1; Fig. 18 e 19)

Leporinus agassizi Géry,1960b; 1972/73; Garavello,1979.

Nome comum: aracu cabeça gorda.

Material examinado: INPA 10110, 4 (50$62 \mathrm{~mm}$ ), Rio Uatumã, Cachoeira do Miriti, abaixo UHE Balbina, 06 outubro/1987; INPA 10111, 19 (46-86mm) Rio Uatumã, Cachoeira Morena, abaixo UHE Balbina, 07 outubro/1987; INPA 10113, 1 (240mm), Rio Uatumã, Cachoeira de Miriti, fevereiro/1985; INPA 10114, 4 (233-260mm), Rio Uatumã, UHE Balbina, fevereiro/1985; INPA 10118, 3 (233-243mm), Rio Uatumã, Igarapé do Arraia, acima cachoeira Balbina, 15 abril/1983; INPA 10119, 1 (284mm), Rio Uatumã, Igarapé do Barreto, UHE Balbina, 27 abril/1983; INPA 10120, 2 (244-256mm), Rio Uatumã, 27 fevereiro/1983; INPA 10121, 2 (235-308mm), Rio Uatumã, novembro/1984; INPA 10122, 1 (236mm), Rio Pitinga, Igarapé Água Branca, 17 abril/1983; INPA 10123, 1 (274mm), Rio Pitinga, Igarapé Água Branca, 17 outubro/1983; INPA 10124, 3 (225-309mm), Rio Uatumã, Igarapé Caititu, acima cachoeira Balbina, 19 outubro/1983.

Comentários: Leporinus agassizi é citada para vários rios da Amazônia, principalmente na área periférica à calha do rio Amazonas. Ela é uma das espécies de anostomídeos que alcança maior porte, chegando a cerca de $350 \mathrm{~mm}$ de comprimento e um quilo de peso e empreende migrações. Grandes cardumes desta espécie, juntamente com Leporinus fasciatus e Laemolyta taeniata foram observados no pé da barragem de Pitinga, em junho e outubro/ 94 , tentanto ultrapassála em direção à montante. Sua alimentação é constituída basicamente de larvas de insetos e material vegetal.

Em vida, os indivíduos adultos geralmente apresentam a porção inferior da cabeça, a região opercular e as nadadeiras peitorais, ventrais e anal alaranjadas e olho vermelho-púrpura. Em exemplares jovens, com até cerca de $100 \mathrm{~mm}$ de comprimento (Fig.19), a faixa longitudinal escura sobre o corpo apresenta-se normalmente fragmentada, sendo a sua porção anterior mais dilatada e em forma de mancha oval ou retangular. Além da faixa longitudinal, ocorre normalmente uma série de 3 ou mais manchas ovais na região humeral, logo abaixo da linha lateral, e 12 a 14 faixas escuras na região dorsal, melhor visualisadas quando o peixe é olhado de cima.

\section{Leporinus uatumaensis sp.n.}

$$
\text { (Tab.1; Fig.20) }
$$

Nome comum: aracu listrado.

Material examinado: HOLOTIPO INPA 10087, $(89 \mathrm{~mm})$, Rio Uatumã, Cachoeira do Miriti, abaixo da cachoeira Balbina, col. S. Amadio, 09 fevereiro/1985; PARATIPOS: MZUSP 51125, (ex INPA 10086), $(90 \mathrm{~mm})$, Rio Uatumã, Igarapé do Arraia, acima da cachoeira Balbina, col. M. Jegu, janeiro/1995; MZUSP 51126, (ex INPA 10154), (102mm), Rio Uatumã, Igarapé Santa Luzia, acima da UHE Balbina, col. S. Amadio, 30 julho/1987; INPA 10535, 8 (67$80 \mathrm{~mm}$ ), mesmos dados de coleta do holotipo.

Descrição: Caracteres morfométricos e merísticos ( Tabs. 1 e 2). Porte pequeno, corpo alongado, boca terminal, lábios finos; dentes no premaxilar, em número de três, dispostos em forma de escada, ligeiramente recurvados na porção terminal, escavados internamente e com contorno plano; dentes da mandíbula, em número de quatro, cônicos a achatados, com extremidade pontuda, decrescendo de tamanho a partir da sínfise, sendo o último atrofiado; cabeça curta, cônica e pontuda; perfil pré-dorsal curvado na ponta do focinho e ligeiramente inclinado a quase reto no dorso, até o 
início da nadadeira dorsal; base da dorsal ligeiramente inclinada; perfil pós-dorsal levemente abaulado; perfil dorsal do pedúnculo caudal ligeiramente côncavo a quase reto; perfil ventral em curva suave, da ponta da mandíbula até o início da nadadeira anal; base da anal ligeiramente inclinada; perfil inferior do pedúnculo caudal côncavo; nadadeira anal curta com extremidade reta, distante da base da caudal.

O colorido de fundo do corpo é castanho claro no dorso, cinza amarelado no ventre e claro na região opercular; uma listra longitudinal escura, ao nível da linha lateral, que vai do nível da dorsal, a partir da $12^{a}$ escama da linha lateral, até a extremidade do pedúnculo caudal e daí se estrende até a extremidade dos raios caudais medianos; esta faixa ocupa a fileira de escamas da linha lateral e meia escama das séries imediatamente acima e abaixo da linha lateral, sendo que ela se expande na sua porção anterior, formando geralmente uma mancha grande, arredondada ou oval, que ocupa cerca de seis escamas de comprimento e duas de altura; além da faixa longitudinal, ocorrem duas manchas escuras na porção anterior do tronco, sendo uma, menor, logo atrás do opérculo e a outra, arredondada e equidistante entre esta e a origem da listra longitudinal; uma série de treze a quatorze bandas escuras transversais no dorso, sendo estas melhor visíveis quando vistas de cima; estas bandas são estreitas e ligeiramente inclinadas para a frente, em direção ao dorso e apresentam a seguinte disposição: uma mais inclinada, atrás das narinas, outra entre as órbitas, outra acima do opérculo, quatro entre o opérculo e o início da nadadeira dorsal, duas na base da dorsal e quatro a cinco entre esta e a nadadeira adiposa; quase sempre ocorrem também duas a dez manchas, ovais ou ligeiramente alongadas sobre o dorso, acima da linha lateral e mais acentuadas na região anterior do corpo, sendo que elas geralmente correspondem às extremidades ou aos pontos de interseção das bandas transversais; a parte anterior da listra longidudinal $\mathrm{e}$ as duas manchas situadas logo à sua frente apresentam o contomo prateado a metálico; nadadeiras uniformemente claras.

Diagnose: Porte pequeno; corpo castanho a amarelado com várias bandas escuras inclinadas sobre o dorso e uma listra escura longitudinal sobre a linha lateral; esta listra iniciase ao nível da nadadeira dorsal e vai até a extremidade do pedúnculo caudal,estendendo-se daí até o final dos raios caudais medianos; além disso, ocorrem duas manchas escuras arredondadas na porção anterior do tronco, imediatamente abaixo da linha lateral e várias outras manchas acima da linha lateral, correspondendo às extremidades ou pontos de interseção das faixas dorsais.

Etimologia: O nome específico uatumaensis refere-se ao rio Uatumã, primeiro grande afluente da margem esquerda do Amazonas, abaixo de Manaus e no qual foi instalada a Usina Hidrelétrica de Balbina.

Discussão: $L$. uatumaensis se enquadra perfeitamente no grupo de espécies de Leporinus com listras 
longitudinais sobre a linha lateral, segundo critérios apresentados por GÉRY (1977) e GARAVELLO (1979). Ela apresenta certas semelhanças com $L$. agassizi, $L$. nigrotaeniatus, $L$. melanopleura e $L$. taeniatus $\mathrm{mas}$ diferencia-se fundamentalmente destas espécies pelos seguintes atributos:

L. agassizi tem um corpo bem mais elevado (altura contida 3,2 a 3,7 vezes no comprimento), maior número de escamas na linha lateral ( 38 a 40) e os adultos não apresentam mancha sobre o corpo além da listra longitudinal e tem a adiposa com um distintivo halo amarelado;

L. nigrotaeniatus tem quatro dentes no pré-maxilar e 40 a 42 escamas na linha lateral (EIGENMANN, 1912).

L. melanopleura é uma espécie originária e restrita à bacias costeiras do nordeste brasileiro (FOWLER, 1930), tem apenas 33 a 36 escamas na linha lateral e apresenta a listra longitudinal contínua sobre todo o tronco, do opérculo à base do pedúnculo caudal (GÉRY, 1960b).

L. taeniatus é uma espécie originária e restrita a bacia do rio São Francisco e apresenta também a listra longitudinal contínua e bem delimitada sobre todo o tronco, do opérculo à base do pedúnculo caudal (GARAVELLO, 1979).

Leporinus uatumaensis sp.n. demonstrou ser uma espécie rara no rio Uatumã, tendo sido coletados apenas onze exemplares no decorrer de várias coletas efetuadas na sua área de ocorrência. Por causa de seu pequeno porte e de seu padrão de colorido, esta espécie apresenta grande potencial para a aquariofilia.

\section{Leporinus megalepis Gunther, 1863}

$$
\text { (Tab.1; Fig.21 e 22) }
$$

Leporinus megalepis Géry et al., 1988; 1991.

Nome comum: aracu pintadinho.

Material examinado: INPA 3209, 2 (69$72 \mathrm{~mm}$ ), Rio Pitinga, jusante UHE Pitinga, 11 outubro/1989; INPA 10037, 3 (40-74 mm), Rio Uatumã, Cachoeira Miriti, 04 outubro/1987; INPA 10038, 3 (34-48mm), Rio Uatumã, jusante UHE Balbina, 24 outubro/1987; INPA 10039, 10 (55$65 \mathrm{~mm}$ ), Rio Uatumã, poço jusante UHE Balbina, 28 outubro/1987; INPA 10040, 1 (92mm), Rio Pitinga, Cachoeira 40 Ilhas, jusante UHE Pitinga, 03 junho/1994; INPA 10041, 4 (43-80mm), Rio Pitinga, Cachoeira $3 \mathrm{a}$, queda, montante UHE Pitinga, 15 janeiro/1995; INPA 10050, 3 (32$60 \mathrm{~mm}$ ), Rio Uatumã, jusante UHE Balbina, 26 outubro/1987; INPA 10136, 2 (33-42 mm), Rio Uatumã, Cachoeira Miriti, abaixo UHE Balbina, 10 outubro/1987.

Comentários: Leporinus megalepis é uma espécie de pequeno porte, alcançando cerca de $60 \mathrm{~mm}$ e distribui-se pelos rios das Guianas Francesa e Inglesa e na periferia da bacia amazônica brasileira (GÉRY et al., 1988), onde predomina áreas de corredeiras.

Em alguns dos lotes examinados os exemplares apresentam as manchas da região abdominal de coloração cinza-metálica, tendo em seus contornos um halo iridescente. As nadadeiras são uniformemente claras, exceto a anal, que tem uma mancha preta alongada sobre os raios medianos.

Leporinus granti Eigenmann, 1912 (Tab.1; Fig.23 e 24)

Leporinus granti Garavello, 1979; Santos \& Jegu, 1989; Géry et al., 1991. 
Nome comum: aracu rabo vermelho. Material examinado: INPA 10096, 2 (177$198 \mathrm{~mm})$, Rio Uatumã, igarapé Barreto, acima cachoeira Balbina, 27 abril/1983; INPA 10097, I (123,5mm), Rio Pitinga, Cachoeira 40 Ihas, abaixo UHE Pitinga, 02 fevereiro/1994; INPA 10098, 1 (152mm), Rio Pitinga, Cachoeira 40 Ihas, 04 junho/ 1994; INPA 10099, 1 (183mm) Rio Pitinga, Cachoeira 40 Ilhas, 12 janeiro/1995; INPA 10101, 3 (104,4-113mm), Rio Uatumã, abaixo barragem Balbina, 21 outubro/98; INPA 10102, 3 (121$146 \mathrm{~mm}$ ) Rio Uatumã, jusante UHE Balbina, 24 outubro/1987; INPA 10104, 2 (90-104mm), Rio Uatumã, Ilha de Nazaré, 16 setembro/1985; INPA 10107, 1 (72mm), Rio Uatumã, tha de Nazaré, 16 setembro/1985; INPA 10109, 8 (53-105mm), Rio Uatumã, jusante UHE Balbina, 28 outubro/1987.

Comentários: Leporinus granti é citada para as Guianas e o rio Aripuanã, afluente do Madeira. Na área do Uatumã ela foi comumente encontrada tanto no leito como nos pequenos afluentes. Em junho/94 foram observados grandes cardumes desta espécie no sopé da barragem de Pitinga e no canal de desvio, tentando atingir a seção à montante. Ela é uma espécie facilmente capturável com anzol e isca de peixe, carne e insetos.

Em vida, os indivíduos apresentam a região ventral do corpo e as nadadeiras intensamente avermelhadas, exceto a adiposa que é cinza. Nos juvenis, com até cerca de $120 \mathrm{~mm}$ de comprimento, o padrão de colorido é totalmente distinto (Fig. 24): nestes ocorrem numerosas manchas escuras sobre o tronco, principalmente sobre a linha lateral e melhor evidenciadas quando o peixe é visto de cima. As manchas que ocorrem ao longo ou logo abaixo da linha lateral normalmente apresentam a seguinte distribuição: duas a três na região humeral; uma (maior e retangular), ao nível terminal da nadadeira dorsal; uma (oval) ao nível da nadadeira anal e a outra (arredondada) na extremidade do pedúnculo caudal; normalmente entre estas duas últimas manchas sobre a linha lateral ocorrem duas manchas menores e diametralmente opostas, sendo uma ao nível do final da adiposa e outra ao nível final da anal.

\section{Leporinus aripuanaensis Garavello \& Santos, 1981. \\ (Tab.1; Fig.25 e 26)}

Leporinus aripuanaensis Garavello \& Santos, 1992.

Nome comum: aracu pintado

Material examinado: INPA 3208, 2 (118$119 \mathrm{~mm}$ ), Rio Pitinga, pé da barragem de Pitinga, 11 outubro/87; INPA 10042, 6 (78,5-92,2mm) Rio Uatumã, jusante UHE Balbina, 26 outubro/1988; INPA 10043, 3 (91,8-99,2mm), Rio Uatumã, Igarapé do Arraia, fevereiro/85; INPA 10044, 12 (54,1$85,1 \mathrm{~mm})$ Rio Uatumā, Iha de Nazaré, jusante UHE Balbina, 16 setembro/1985; INPA 10045, 5 (53,1$59,3 \mathrm{~mm})$, Rio Uatumã, Cachoeira Morena, jusante UHE Balbina, 7 outubro/1987; INPA 10046, 3 (49. $64 \mathrm{~mm}$ ) Rio Uatumã, Cachoeira de Miriti, 04 outubro/ 1987; INPA 10049, 6 (69,6-84,1MM), Rio Uatumã, pé da barragem da UHE Balbina, 24 outubro/87.

Comentários: Leporinus aripuanaensis só foi citada até o presente para o rio Aripuanã, afluente da margem direita do Madeira $\mathrm{e}$ tem sido coletada somente em áreas de corredeiras com fundo arenopedregoso. Nos indivíduos maiores as faixas transversais limitam-se ao dorso, sendo que nos jovens estas geralmente ultrapassam o nívelda linha lateral, algumas chegando a atingir o abdomen (Fig. 26).

Leporinus cylindriform is Borodin, 1929

(Tab.1; Fig.27 e 28)

Leporinus cylindriformis Garavello, 1979; 
Santos, 1991.

Nome comum: aracu pintado.

Material examinado: INPA 10070, 1 (176mm), Rio Pitinga, Cachoeira Travessão, jusante UHE Pitinga, 06 fevereiro, 1994; INPA 10075, 2 (138-140mm), Rio Uatumã, 5Km acima UHE Balbina, 21 fevereiro/1983; INPA 10076, 3 (162-182mm), Rio Uatumã, Igarapé do Arraia, acima UHE Balbina, 15 abriv1983; INPA 10078, 3 (180-195mm), Rio Uatumã, 15 outubro/1983; INPA 10079, 1 (175mm), Rio Uatumã, UHE Balbina, fevereirol 1985; INPA 10080, 2 (175-176mm), Rio Uatumã, UHE Balbina, fevereiro/1985; INPA 10081, 3 (150-179mm), Rio Uatumã, Igarapé Água Branca, acima cachoeira Balbina, janeiro/1985; INPA 10082, 1 (115mm), Rio Uatumã, jusante UHE Balbina, 26 outubro/1987; INPA 10133, 2 (50-53mm), Rio Uatumã, Cachoeira Morena, abaixo UHE Balbina, 07 outubro/1987.

Comentários: Leporinus cylindriformes tem sido citada apenas para os rios Amazonas (GARAVELLO, 1979) e Jamari (SANTOS, 1991). No rio Uatumã ela foi capturada tanto no leito, como nas áreas de corredeiras e nos pequenos afluentes.

Nos juvenis, com até cerca de $100 \mathrm{~mm}$ de comprimento (Fig.28), além das manchas arredondadas, comuns nos adultos, ocorrem 11 a 13 faixas escuras, transversais sobre o dorso, bem visíveis quando o peixe é visto de cima. Além das três manchas arredondadas, ao nível da linha lateral, ocorrem outras manchas na região anterior do corpo, logo abaixo da linha lateral.

\section{Leporinus friderici (Bloch,1794)}

$$
\text { (Tab.1; Fig.29 e 30) }
$$

Salmo friderici Bloch, 1794; Leporinus friderici Géry, 1977; Garavello, 1979; Santos, 1982.

Nome comum: aracu cabeça gorda.

Material examinado: INPA 2732, 1 (261 mm), Rio Uatumã, Arraia, acima cachoeira Balbina, setembro/ 1985; INPA 10115, 7 (208-255mm), Rio Uatumã, UHE Balbina, janeiro/1985; INPA 10132, 4 (48-68mm), Rio Pitinga, Igarapé na rodovia que leva à cachoeira 40 Ilhas, jusante UHE Pitinga, 05 junho/94;
Comentários: Leporinus friderici é uma espécie citada para as bacias do Amazonas e Paraná-Paraguai, além de bacias costeiras do nordeste. Esta área de distribuição tão vasta, aliada às grandes variações dos caracteres citados para esta espécie, sugerem que provavelmente se trata de um conjunto de variedades ou mesmo de espécies críticas.

Nos juvenis, com até cerca de $70 \mathrm{~mm}$ (Fig. 30), ocorre uma série de 13 a 15 faixas transversais, restritas ao dorso e uma a duas manchas arredondadas incipientes na região humeral, abaixo da linha lateral.

\section{Leporinus pitingai sp.n.}

$$
\text { (Tab.1; Fig.31) }
$$

Nome comum: aracu, piau

Material examinado: INPA 10126, Holótipo $(285 \mathrm{~mm})$, Rio Pitinga, Cachoeira 40 Inhas, abaixo UHE Pitinga, col. G.M.Santos, 6 abril/1994; MZUSP 48960 (ex INPA 10125), Parátipo (315mm), Rio Pitinga, Cachoeira Travessão, abaixo UHE Pitinga, col. Michel Jegu, 7 fevereiro/1994; INPA 10127, parátipo $(212 \mathrm{~mm})$, Rio Pitinga, Cachoeira Travessão, abaixo UHE Pitinga, col, G.

M. Santos, 8 abril/1994.

Diagnose: Porte médio a grande; seis a sete manchas escuras de diversas formas e tamanhos ao longo da linha mediana do corpo, quarenta e uma a quarenta e quatro escamas na linha lateral, seis séries de escamas acima da linha lateral, quatro dentes no pré-maxilar e quatro no dentário.

Descrição: Dados morfométricos e merísticos (Tabs. 1 e 2). Porte médio a grande, chegando a cerca de $315 \mathrm{~mm}$ de comprimento; corpo alongado e alto na região pré-dorsal; perfil da cabeça triangular; boca terminal; o lábio superior projeta-se sobre o inferior, deixando a boca ligeiramente 
voltada para baixo, quando fechada; perfil dorsal abaulado sobre a ponta do focinho, ligeiramente inclinado a quase reto no topo da cabeça e inclinado na região pré-dorsal; base da dorsal inclinada; região pós-dorsal levemente inclinada; perfil dorsal do pedúnculo caudal côncavo; perfil abaulado na ponta da mandíbula, inclinado na cabeça e uniformemente abaulado do istmo à base da nadadeira anal; base da anal inclinada; perfil ventral do pedúnculo caudal reto; dentes do prémaxilar em número de quatro, cônicos, escavados internamente, alinhados em forma de escada e decrescendo paulatinamente de tamanho a partir da sínfise; dentes da mandíbula, em número de quatro, incisiviformes e decrescendo de tamanho a partir da sínfise; nadadeira anal relativamente longa, chegando perto da base da caudal, exceto no holotipo, onde parece ter sido danificada e posteriormente regenerada; coloração de fundo cinza escura na região dorsal, amarelo clara no ventre e alaranjada na porção inferior da cabeça; normalmente seis a sete manchas escuras no corpo, ao longo da linha lateral, com diferentes formas e tamanhos e apresentando a seguinte disposição: a primeira, na região humeral, iniciando-se logo após o opérculo; a segunda, iniciando-se ao nível da extremidade da nadadeira peitoral; a terceira, maior de todas, ao nível mediano da nadadeira dorsal; a quarta, geralmente arredondada, iniciando-se ao nível da quarta fileira de escamas atrás da dorsal; a quinta, arredondada e geralmente fragmentada, em frente à vertical que passa pela origem da nadadeira anal e a última, na extremidade do pedúnculo caudal. A mancha maior, localizada ao nível da dorsal, ocupa cerca de tres a cinco escamas tanto horizontal como verticalmente; no holotipo a última mancha é estreita e bastante alongada, ocupando sete escamas e esmaecida nos parátipos. Nadadeiras dorsal e caudal cinzaescuras, sendo que a dorsal apresenta sua porção terminal mais escura que a base; nadadeira peitoral cinza-escura; nadadeiras ventral e anal amareladas.

Etimologia: O nome específico pitingai refere-se ao rio Pitinga, afluente do Uatumã, estado do Amazonas, na bacia do qual foi construída a Usina Hidrelétrica de Pitinga.

Discussão: As espécies de Leporinus são geralmente agrupados de acordo com seu padrão de colorido, sendo a forma e o número de manchas sobre o corpo dos adultos um dos caráteres mais distintivos (GÉRY, 1977; GARAVELLO, 1979). Segundo os critérios adotados por GERY (1977), há quatro grupos básicos de espécies: o primeiro caracterizado por faixas transversais, tipo Leporinus trifasciatus; o segundo por uma a quatro manchas arredondadas sobre a linha lateral, tipo $L$. friderici; o terceiro por listras longitudinais, tipo $L$ agassizi e o último pela ausência de manchas ou no máximo uma mancha na extremidade do pedúnculo caudal, tipo L. brunneus.

De acordo com estas categorias, L. pitingai não se enquadra bem em nehum dos quatro grupos, pois apresenta um número bem maior de manchas sobre a linha lateral, sendo que estas não chegam a formar faixas transversais como as 
demais espécies conhecidas deste grupo.

L. pitingai difere do grupo de espécies de Leporinus definidos por GARAVELLO (1979) para agregar as espécies de pequeno porte e com grande número de manchas sobre o corpo (p.ex. $L$ megalepis) pelo fato de seu porte grande e não apresentar nenhuma mancha acima ou abaixo da linha lateral, como ocome com as espécies deste grupo.

O padrão de colorido da maioria das espécies de Leporinus, bem como das demais espécies de anostomídeos, varia acentuadamente com o desenvolvimento ontogenético (GARAVELLO, 1979; SANTOS, 1982), entretanto pelo tamanho apresentado, os exemplares analisados de L pitingai são todos adultos, o que a torna facilmente distinta das demais espécies conhecidas do grupo.

L pitingai apresenta um padrão de colorido ligeiramente semelhante à $L$ trifasciatus, $L$ cylindriformes, mas difere destas espécies pelos seguintes caracteres: de $L$ trifasciatus, por apresenta um número maior de manchas sobre o tronco (sete, contra apenas três) e de dentes em ambas as maxilas (quatro ao invés de três); Ela difere basicamente de $L$. cylindriformes por apresentar um corpo bem mais elevado (altura contida 3,6 a 3,7 no comprimento padrão contra 4 a 4,7) e manchas em maior número e tamanho sobre a linha lateral.

Leporinus pitingai é uma espécie rara no Uatumã, já que apenas três exemplares foram encontrados na região, após dezenas de coletas. Todos os exemplares capturados foram provenientes de áreas de corredeiras, indicando ser este o biótopo preferencial desta espécie.

\section{DISCUSSÃO E CONCLUSÕES}

Das vinte e duas espécies de anostomídeos inventariadas na bacia do Uatumã, doze espécies, ou seja, cerca da metade, são pertencentes ao gênero Leporinus. Este gênero é formado por cerca de 60 espécies (GARAVELLO, 1979), englobando aproximadamente $50 \%$ das espécies conhecidas de anostomídeos. Laemolyta, Pseudanos e Anostomus apareceram com duas espécies e Schizodon, Anostomoides, Synaptolaemus e Gnathodolus, com uma espécie cada.

O número de espécies inventariadas na bacia do Uatumã foi muito elevado, tendo em vista tratar-se de um rio de pequeno a médio porte em termos de bacia amazônica e onde, em inventário feito anteriormente, só haviam sido assinaladas quinze espécies (AMADIO, 1985).

Inventários feitos em outros rios da Amazônia, como Tocantins (SANTOS \& JEGU, 1989), Jamari (SANTOS, 1991) e Trombetas (FERREIRA, 1992) indicam que o número médio de espécies de anostomídeos, em cada um destes rios, oscila em torno de vinte.

Apesar da quantidade aproximadamente igual de espécies de anostomídeos nos diferentes rios da Amazônia, observa-se no entanto, uma grande diferenciação quanto à sua composição específica: Entre os rios Tocantins e Uatumã, por exemplo, apenas sete espécies foram comuns e entre o Uatumã e o Jamari, apenas doze. Estes dados mostram que apesar da bacia Amazônica ser formada por um sistema hidrográfico contínuo, ela, 
na verdade, é formada por sub-bacias que encerram uma ictiofauna diferenciada e com alto grau de endemismo.

Esta distribuição descontínua e em forma de mosaico das espécies de anostomídeos deve estar associada tanto às diferentes características limnológicas observadas na atualidade entre os rios de água preta, branca ou clara (SIOLI, 1968; JUNK \& FURCH, 1980), como à eventos vicariantes ocorridos no passado, principalmente aqueles relacionados às glaciações e que provocaram uma variação do nível do mar em torno de 100 metros, com o consequente isolamento de populações, submetidas a um intenso processo de especiação (HAFFER, 1982; RENNO et al., 1990).

Sete espécies de anostomídeos do Uatumã (Leporinus fasciatus, $L$. friderici, L. desmotes, L. agassizi, Schizodon fasciatus, Laemolyta taeniata e $L$. varia) podem ser consideradas comuns e com ampla distribuição por toda a bacia amazônica central; as demais espécies, sobretudo as dos gêneros Anostomus, Pseudanos, Gnathodolus e Synaptolaemus, são relativamente raras, tendo sido encontradas apenas nos altos cursos de rios periféricos à grande calha do sistema Solimões/Amazonas. Duas espécies (Leporinus uatumaensis $\mathrm{sp} . \mathrm{n}$ e L. pitingai sp.n.) foram descritas como novas e até o momento só foram encontradas na bacia do Uatumã.

Os dados de coleta $\mathrm{e}$ as observações feitas em campo indicam que a maioria das espécies de anostomídeos do Uatumã é restrita a determinados trechos do rio ou apresentam preferências por determinados biótopos: os peixes de pequeno porte, como as espécies de Pseudanos, Anostomus, Synaptolaemus e Gnathodolus, além de Leporinus granti e L. megalepis só ocorreram em zonas de corredeiras. Outras espécies, como Schizodon fasciatus e Laemolyta varia ocorreram geralmente no baixo curso e em áreas inundadas.

A maioria das espécies de anostomídeos inventariadas é de pequeno a médio porte, sendo que quatro espécies (Leporinus fasciatus, $L$. frideriri, L. agassizi e Schizodon fasciatus) são bem populares e apresentam porte relativamente grande, em torno de $300 \mathrm{~mm}$ de comprimento e tem uma certa importância na pesca local, principalmente à jusante das barragens, onde elas se aglomeram durante os movimentos migratórios em direção à montante.

Algumas espécies de pequeno porte que são intensamente coloridas, como Synaptolaemus cingulatus, Leporinus megalepis, Pseudanos gracilis, $P$. trimaculatus e Anostomus ternetzi apresentam grande potencial na aquariofilia.

Foi observado que o padrão de colorido de várias espécies de anostomídeos sofre acentuada variação durante o desenvolvimento ontogenético, havendo uma tendência dos jovens terem um grande número de faixas transversais sobre o dorso, as quais sofrem uma redução gradativa com o crescimento dos indivíduos. Tal fenômeno já foi assinalada para algumas espécies dos gêneros Leporinus (GARAVELLO, 1979), Laemolyta (SANTOS, 1982) e Rhytiodus (SANTOS, 1980). 
Tabela 1. Caracteres meristicos e morfométricos das espécies estudadas $(C=$ comprimento; Ex= exemplares; $d=$ diâmetro; $L L=$ linha lateral; Ped $=$ pedúnculo caudal).

\begin{tabular}{|c|c|c|c|c|c|c|c|c|c|c|c|c|c|c|c|c|c|c|c|c|}
\hline \multirow[t]{2}{*}{ Espécie } & \multirow[t]{2}{*}{ Ex. } & \multirow[t]{2}{*}{ C.Padrāo } & \multicolumn{5}{|c|}{ Escamas } & \multicolumn{5}{|c|}{ Raios } & \multirow[t]{2}{*}{ Dentes } & \multicolumn{7}{|c|}{ Proporçōes Corporals } \\
\hline & & & $\mathrm{LL}$ & acima LL & abaixo LL & Ped. & Pré dorsal & Interdorsal & Dorsal & Peitoral & Ventral & Anal & & Altura & Cabeça & C. Ped. & A. Ped. & Focinho & d. orbilal & Interorbital \\
\hline Gnathodolus bidens & 2 & $92+113.5$ & $38-39$ & 5 & $4-4.5$ & 16 & $8-10$ & $8-10$ & ii, 10 & $i, 13-15$ & 1,8 & 11,8 & $4 / 1$ & 3.4-3.7 & $3.5 \cdot 3.8$ & $5.2-6.2$ & $7.9 \cdot 8.4$ & $2.3-2.7$ & 3.3-3.7 & 2.5 \\
\hline Synaptolaemus cingulatus & 19 & $29 \cdot 104$ & $36-38$ & 4 & 3 & 12 & $9-12$ & $9-11$ & ii. 10 & $i, 14-16$ & $i, 8$ & i., 8 & $4 / 4$ & 4.1 .5 & 3.7 .4 .2 & $5.6 \cdot 6.7$ & $8.6-9.8$ & $2.3-2.8$ & $3.5-4.8$ & $3-3.7$ \\
\hline Anostomus ternetzi & 30 & $24 \cdot 70$ & $39-41$ & 5 & 4 & 16 & $10-13$ & $11-14$ & ii. 10 & $i .12-14$ & $i, 8$ & i., 8 & $4 / 4$ & $4.7-5.8$ & $3.6-4.3$ & $6.4-8.1$ & $9.7-12$ & $2.2-3.3$ & $3.2-4$ & $2.5-3.5$ \\
\hline Anostomus plicatus & 1 & 65 & 39 & 5 & 4 & 16 & 12 & 13 & ii. 10 & $\mathrm{i}, 14$ & 1,8 & $i i, 8$ & $4 / 4$ & 4.6 & 3.6 & 8.1 & 9.3 & 2.8 & 4.5 & 3.3 \\
\hline Pseudanos gracilis & 5 & $128.5-149.3$ & 44.45 & 5 & $4-4.5$ & 16 & $13-14$ & $14 \cdot 15$ & ii. 10 & i.13-15 & $\mathrm{i}, 8$ & 11,8 & $4 / 4$ & $4.7-5.2$ & 4.7.4.9 & $7.2-8.3$ & $10.4-10.6$ & $2.8-2.9$ & $3.9-4.5$ & $2.4-2.7$ \\
\hline Pseudanos trimaculatus & 7 & $123.8 \cdot 172$ & $42-43$ & 5.5 .5 & $4.5 \cdot 5$ & 16 & $12-14$ & $11-15$ & ii. 10 & $i, 13-14$ & $i, 8$ & $i i, 8$ & $4 / 4$ & $3.2-3.6$ & $4.3 \cdot 4.6$ & $7-8.5$ & $8.4 \cdot 10$ & $2.8-3.4$ & $4-4.4$ & $2.3-2.6$ \\
\hline Anostomoides laticeps & 15 & $194-250^{\circ}$ & $42-44$ & $5.5-6.5$ & 4.5 & 16 & 11.14 & 12.15 & $1 i, 10$ & $i, 13 \cdot 15$ & $i, 8$ & $\mathrm{ii}, 8$ & $4 / 4$ & $3.2 \cdot 3.8$ & $4-4.5$ & $6.8-8.1$ & $9 \cdot 10.6$ & $2.3 \cdot 2.7$ & $3.4 \cdot 3.9$ & $1.8-2.1$ \\
\hline Laemolyta taeniata & 21 & $145 \cdot 236$ & $43-45$ & 5 & 4.4 .5 & 16 & $11 \cdot 14$ & $13-17$ & $\mathrm{ii,10}$ & $0.12-15$ & 1,8 & $i 1,8$ & $4 / 4$ & $4-4.8$ & $4.8-5.3$ & $6.7 \cdot 7.9$ & $11.3-12.5$ & $2.5-2.9$ & $3.6-5$ & $2.1-2.5$ \\
\hline Laemolyta varia & 13 & 168.7 .259 .3 & $45-47$ & 6 & 5.5 .5 & 16 & $10-14$ & $12-16$ & ii. 10 & $i, 12-14$ & 1,8 & 11,8 & $4 / 4$ & $3.7-4.2$ & $4.7 \cdot 5.3$ & $6.6 \cdot 7.5$ & $10 \cdot 11.5$ & $2.4-2.9$ & $3.6-4.3$ & $1.9-2.3$ \\
\hline Schizodon fasciatus & 10 & $250-313$ & $42-44$ & $4.5 \cdot 5$ & $4 \cdot 5$ & 16 & $10-13$ & $15-17$ & $\mathrm{ii}, 10$ & $\mathrm{i}, 15-16$ & $i, 8$ & $\mathrm{i}, \mathrm{i}, 8$ & $4 / 4$ & $3.6-4.1$ & $4.4-5.2$ & 7.8 .2 & $9.3 \cdot 10.2$ & $2.1 \cdot 2.7$ & 4.1 .5 .1 & $1.6-1.9$ \\
\hline Leporinus pachycheilus & 6 & $185-250$ & 40.42 & 5 & 4.4 .5 & 12 & $11-15$ & $12 \cdot 14$ & $\mathrm{ii}, 9 \cdot 10$ & $i, 15-16$ & 1,8 & ii,8 & $4 / 4$ & $4.3 \cdot 4.8$ & $4.6-5.1$ & $7.5 \cdot 9$ & $10-10.8$ & $2.4 \cdot 2.7$ & $4-4.7$ & $2.2-2.5$ \\
\hline Leporinus fasciatus & 17 & $79 \cdot 264$ & $43-45$ & $7 \cdot 7.5$ & 6 & 16 & $12-16$ & $12-14$ & $\mathrm{ii}, 10$ & $i, 14-16$ & $1,8 \cdot 9$ & $\mathrm{ii}, 8$ & $4 / 4$ & $3.7 \cdot 4.3$ & $3.9 \cdot 4.3$ & $7.7-8.5$ & $10.2-11.3$ & $2.3-2.6$ & $4-5.6$ & $2.2 \cdot 2.8$ \\
\hline Leporinus desmotes & 21 & $75 \cdot 137$ & $37-39$ & 5.6 & $4.5 \cdot 5$ & 14 & 9.12 & $9-12$ & ii, 10 & $i, 14-16$ & $1,8-9$ & ii,8-9 & $4 / 4$ & $3.7 \cdot 4.1$ & $3.9 \cdot 4.4$ & $7.1-8.6$ & $9.4-10.4$ & -2.44 & $2.9-4.3$ & $2.4 \cdot 2.9$ \\
\hline Leporinus brunneus & 10 & $147-306$ & $41-42$ & 5.5 .5 & 4.4 .5 & 16 & $11-12$ & $11 \cdot 13$ & $\mathrm{ii,10}$ & $i, 15-16$ & 1,8 & ii.8 & $4 / 4$ & $4-4.9$ & $3.9 \cdot 4.5$ & $5.9 \cdot 7.1$ & $11.3 \cdot 12.1$ & $2.2-2.4$ & 4.4-6 & $2.4-3$ \\
\hline Leporinus agassizi & 41 & $62 \cdot 309$ & 38.40 & 5.5 .5 & 4.5 .5 & 16 & $10-12$ & 11.13 & ii. 10 & i.14-16 & 1,8 & ii. 8 & $4 / 4$ & $3.2-3.7$ & $3.6 \cdot 4.2$ & $6-7.5$ & $9.3-10.5$ & $2.2-2.8$ & $3.2-5.3$ & $2.1-2.8$ \\
\hline Leporinus uatumaensis sp. $n$. & 11 & $71.5-102$ & $36-37$ & $4.5-5$ & $4.5 \cdot 5$ & 16 & $9-12$ & 9.13 & ii. 10 & $i, 13-14$ & 1,8 & ii,8 & $4 / 4$ & $3.7-4.5$ & $4.4-3$ & $6.8-8$ & $10.2-11.5$ & $2.7 \cdot 2.9$ & $3 \cdot 3.7$ & $2.3 \cdot 2.7$ \\
\hline Leporinus megalepis & 28 & $32-92$ & $33-35$ & $4.5-5$ & $3.5 \cdot 4$ & 16 & $9-12$ & $8-11$ & ii. 10 & $i, 13-14$ & 1,8 & 11,8 & $4 / 4$ & $3.5-4.2$ & $3.8 \cdot 4.5$ & 7.8 .8 & $8.4-10.5$ & $2.4-3$ & $2.8 \cdot 3.6$ & $2.3-2.9$ \\
\hline Leporinus granti & 22 & $53 \cdot 198$ & $35-36$ & 5 & $4 \cdot 4.5$ & 16 & $8-11$ & $9 \cdot 12$ & $1 \mathrm{i}, 10$ & $i, 14 \cdot 15$ & 1.8 & ii,8 & $4 / 4 \cdot 5$ & $2.9-3.6$ & $3.7 \cdot 4.2$ & $6.8 \cdot 8$ & $8-9$ & $2.3 \cdot 2.8$ & $3.6-5$ & $2.2-2.9$ \\
\hline Leporinus anipuanaensis & 37 & $49-119$ & $38-39$ & 5 & 4.4.5 & 16 & $8-12$ & $9-13$ & $\mathrm{ii}, 9 \cdot 10$ & $1,14-16$ & 1,8 & $1 i, 8$ & $4 / 4$ & 4.1 .5 & 4.4 .3 & $7.8-8$ & $10.3-12$ & $2.4 \cdot 2.8$ & $3.4 \cdot 4.1$ & $2.6-3.2$ \\
\hline Leporinus cylindriformes & 16 & $115-195$ & $41-43$ & 5 & $4.5 \cdot 5$ & 16 & $10-14$ & $11 \cdot 15$ & $i 1,10$ & $i, 14 \cdot 16$ & 1,8 & 11.8 & $4 / 4$ & $4-4.7$ & $4.2-4.6$ & $7.4-9.3$ & $11.6-13$ & $2.2-2.5$ & $3.8 \cdot 4.5$ & $2.3-29$ \\
\hline Leporinus friderici & 12 & $208-261$ & $38-39$ & 5 & $4.5-5$ & 16 & $9-11$ & $10-12$ & ii, 10 & $i, 14-16$ & $i .8$ & 11.8 & $4 / 4$ & $3.1-3.6$ & $3.9-4.3$ & $7.9 \cdot 8.4$ & $9.9-10.8$ & $2.3 \cdot 2.7$ & $4.5 \cdot 5.1$ & $2.1-2.4$ \\
\hline Leporinus pitingai $s p . n$. & 3 & $212-315$ & $41-44$ & 6 & 5 & 16 & $12-14$ & $12 \cdot 13$ & ii, 10 & $i, 16-17$ & $1,8-9$ & $1 i, 8$ & $4 / 4$ & $3.6 \cdot 3.7$ & $4.1 \cdot 4.2$ & $6.4-7.8$ & $9.6-10.8$ & $2.5-2.6$ & $4.7-4.8$ & $2.1-2.5$ \\
\hline
\end{tabular}


Tabela 2. Dados morfométricos e merísticos dos holótipos de Leporinus pitingai sp. n. e Leporinus uatumaensis sp. $\mathrm{n}$.

\section{L pitingai sp. $n$.}

Comprimento padrão

Altura do corpo

Comprimento da cabeça

Comprimento do focinho

Diametro orbital

Distância interorbital

Distância pré-dorsal

Distância pré-ventral

Distância pré-anal

Distância interdorsal

Comprimento pedúnculo caudal

Altura pedúnculo caudal

Escamas linha lateral

Escamas acima linha lateral

Escamas abaixo linha lateral

Escamas circumpedunculares

Escamas pré-dorsais

Escamas interdosais

Raios dorsais

Raios peitorais

Raios ventrais

Raios anais

Branquiostégios

Dentes

\begin{tabular}{|c|c|}
\hline 285,0 & 89,0 \\
\hline 85,0 & 23,0 \\
\hline 67,5 & 21,5 \\
\hline 27,0 & 7,5 \\
\hline 14,0 & 5,5 \\
\hline 32,0 & 8,0 \\
\hline 122,0 & 41,0 \\
\hline 135,0 & 45,0 \\
\hline 240,0 & 72,0 \\
\hline 84,0 & 25,0 \\
\hline 44,5 & 12,6 \\
\hline 29,5 & 10,6 \\
\hline 44 & 37 \\
\hline 6 & 5 \\
\hline 5 & 5 \\
\hline 16 & 16 \\
\hline 12 & 10 \\
\hline 12 & 13 \\
\hline ii, 10 & $\mathrm{ii}, 10$ \\
\hline$i, 16$ & $\mathrm{i}, 14$ \\
\hline $\mathrm{i}, 8$ & $\mathrm{i}, 8$ \\
\hline $\mathrm{ii}, 8$ & $i i, 8$ \\
\hline 4 & 4 \\
\hline $4 / 4$ & $3 / 4$ \\
\hline
\end{tabular}


A observação de que cardumes de $L$. agassizi, $L$ fasciatus, $L$. granti $e$ Laemolyta taeniata se aglomeram no sopé da barragem de Pitinga, nos meses de junho e outubro/94, é uma evidência de que estas espécies empreendem migrações ascendentes ao longo da bacia do Uatumã. Isso mostra que estas barragens são um obstáculo intransponível e que se constituem num sério risco à integridade $\mathrm{e}$ manutenção de suas populações, sobretudo para aquelas mantidas à montante do barramento e restritas a um pequeno segmento do rio, sem acesso ao curso inferior, onde normalmente se dá a desova e a criação de larvas e alevinos.

Pelo fato de que as diferentes subbacias hidrográficas da Amazônia possuem uma ictiofauna própria, com alto grau de endemismo e também de que o barramento dos rios tanto compromete a integridade das populações como ocasiona extinção local, principalmente nas áreas de corredeiras, o inventário ictiofaunístico nas áreas submetidas à este tipo de impacto constitui-se num dado histórico e é de fundamental importância para a compreensão do grau de diversidade e do padrão de distribuição dos peixes na Amazônia.

\section{AGRADECIMENTOS}

Os autores agradecem às empresas Eletronorte e Paranapanema, pelo apoio logístico às atividades de campo; aos "referees" e Efrem Ferreira, pelas sugestões quanto à forma do trabalho; aos pesquisadores e técnicos do INPA, pela participação nas coletas do material; à João Paulo, pela tradução do resumo; à Marcelo Garcia pela leitura do texto; à Cristiany Apolinário e
Sulamita Silva, pela ajuda nos trabalhos de laboratório.

\section{Bibliografia citada}

AGASSIZ,L. 1829. Selecta genera et species piscium quos in intinere per brasiliam (1817-1820)... collegit... Dr. J.B. de Spix Munich (Charac: 41-46; 57-79).

AMADIO,S.A. 1985. Estudos de ecologia e controle ambiental na região do reservtório da $U H E$ de Balbina. Sub-projeto Estimativa da ictiofauna. Relatórios técnicos. Convênio ELN-CNPg/INPA. Manaus,AM.

BLOCH,M.E. 1785-1795. Naturgeschichte der auslaendischen fische. Atlas: 1-324.

BORODIN,N.A. 1929. Notes on some species and subspecies of the genus Leporinus Spix. Mem. Mus. Comp. Zool. Cambridge Mass, 50: 269-290.

BRITSKI,H.A. 1976. Sobre uma nova espécie Leporinus da Amazônia. Acta Amazonica 6 (4), Supp. 87-89.

EIGENMANN,C.H. 1912. The freshwater fishes of British Guiana including a study of the ecological grouping of the species and the relation of fauna of the plateau to that of the lowlands. Mem. Carn. Mus., 5: 11-578.

ELETRONORTTE 1976. Estudos Amazônia. Aproveitamento hidrelétrico do rio Uatumã, em Cachoeira Balbina. Estudos de viabilidade. Relatório final, volume IV. paginação variada.

FERNANDEZ-YEPES,A. 1949. Anostomus ternetzi nuevo anostomido de Sur America, colectado en Palital, Estado Guarico, Venezuela. Bol. Soc. Venez. Cienc. Nat, 11: 293-295.

FERREIRA,E.J.G. 1992. A ictiofauna do rio Trombetas na área de influência da futura usina hidrelétrica de Cachoeira Porteira, Pará. Tese de Toutorado, FUA/INPA. Manaus, 162p.

FERREIRA,E.J.G.; ZUANON, J.A.S.; SANTOS,G.M. (No prelo), Catálogo dos peixes comerciais do médio Amazonas: região de Santarém, Pará. Gráfica Ibama. 
FOWLER,H.W. 1930. Os peixes de água doce do Brasil. Arq. Zool. SP. vo.VI: 205-404.

FOWLER,H.W. 1914. Fishes from the Rupununi river, British Guiana. Proc. Acad. Nat. Sci. Philad. 66:229-284.

GARAVELLO,J.C. 1979. Revisão taxonômica do gênero Leporinus Spix, 1829. Tese de Doutorado. USP. 451p

GARAVELLO,J.C.; SANTOS,G.M. 1981. Duas espécies novas do gênero Leporinus Spix, 1829, da bacia do rio Aripuanã, estado do Mato Grosso (Pisces, Anostomidae). Anais do III Encontro de Zoologia do Nordeste, Recife, Brasil: 188.

GARAVELLO,J.C.; SANTOS,G.M. 1992. Leporinus trimaculatus, a new spcies from Amazonia, Brazil, and redescription of the sympatric Leporinus aripuanaensis (Pisces, Characiformes, Anostomidae). Bull. Zool. Mus. Unv. van Amsterdam, 13 (12): 109-117.

GARMAN,S.W, 1890. On the species of the genus Chalcinus in the Museum of comparative zoology at Cambridge. Mass. USA. On species of Gasteropelecus, Cynopotamus and Anostomus. Bull. Essex Inst. Salem, 22 (1-3):1-23

GÉRY,J. 1960a. Contributions à l'etude des poissons characoides. 14. Révision de la super-espèce Anostomus anostomus (L.) et description de formes nouvelles: $A$. brevior et $A$. anostomus longus (Erythrinidae, Anostominae), Bul. Mus. Nat. Hist. Nat: 32: 498-505.

GÉRY,J. 1960b. Contributions to the study of the Characoid fishes. Some South American characoid fishes in the Senckenberg Museum, with the description of a new Leporinus. Senck, Biol., 41: 273-288.

GÉRY,J. 1961. Contributions à l'étude des poissons Characoides. 13. Structures et évolution des Anostominae. Bull. Aquat. Biol.,, 2(19): 93-112.

GÉRY,J, 1972/73. Notes sur quelques Anostomidae (Pisces, Characoidei) du bassin Amazonien. Vie Millieu, 23: fasc.1 (C): 143-175.
GÉRY,J. 1977. Characoids of the world. T.F.H Publ., Neptune City, 672 p.

GÉRY.J., PLANQUETTE,P; LE BAIL,P.Y 1988 - Nomenclature des espèces du groupe Leporinus maculatus et formes affines des Guyanes (Pisces, Characoidei, Anostomidae). Revue Suisse Zool., 95 (3): 699-713.

GERY,J., PLANQUETTE,P.; LE BAIL,P.Y. 1991

- Faune characoide (Poissons ostariophysaires) de L'Oyapock, L'Approuague et la riviere de Kaw (Guyane Française). Cybium 1991, 15(1) Suppl: 1-69.

GUNTHER,A. 1863. On new species of fishes from the Essequibo. Ann. Mag. Nat. Hist. London. 3 (12): 441-443

HAFFER,J. 1982. General aspects of the refuge theory, In. Biological diversification in the Tropics. (G.T.Prance, ed.):6-26. N.Y., Columbia Univ. Press.

JEGU,M.; SANTOS,G.M. 1988. Le genre Serrasalmus (Pisces, Serrasalmidae) dans le bas Tocantins (Bresil, Pará) avec Ia description d'une espece nouvelle, Serrasalmus geryi, du bassin AraguaiaTocantins. Rev. Hydrobiol. Trop., 21 (3): 239-274.

JUNG,W.J.; FURCH,K. 1980. Química da água e macrófitas aquáticas de rios e igarapés na Bacia Amazônica e nas áreas adjacentes. Acta Amazonica, 10 (3): 611-633.

KNER,R. 1859. Zur familie der Characinan III. Folge der ichthyologiscen Beitraege. Densk, Kaiser. Akad. Wiss. Wien, 17: 136-182.

KNOPPEL,H.A. 1970. Food of central amazonian fishes. Contribution to the nutrient ecology of amazonian rain forest streams. Amazoniana, 2 (3): 257-352.

LEITE,R.G. 1987. Alimentação e hábitos alimentares dos peixes do rio Uatumã na área de abrangência da Usina Hidrelétrica - Balbina, Amazonas, Brasil. Dissertação de Mestrado. INPA/FUA. Manaus, 81p.

MYERS,G.S. 1927. Descriptions of new South American fresh-water fishes collected by $\mathrm{dr}$. Carl Ternetz. Bull. Mus. Comp. Zool. Harvard College, vol. LXVIII., 8:108-135.

MYERS,G.S. 1950. Studies on South American fresh-water fishes. II. The genera of Anostomine Characids. Stanford 
Ichthyological Bulletin 3: 184-198.

PLOEG,A. 1986. The cichlid genus Crenicichla from the Tocantins river state of Pará, Brazil, with descriptions of four new species (Pisces, Perciformes, Cichlidae). Beaufortia, 36 (5): 57-80.

RADAMBRASIL 1976 - Programa de integração nacional. Levantamento de recursos naturais. Ministério das Minas e Energia. Departamento Nacional da Produção mineral. Volume 10.510p

RENNO,J,F. 1990. Intraspecific genetic differentiation of Leporinus friderici (Anostomidae, Pisces) in French Guiana and Brazil: a genetic approach to the refuge theory. J.Fish Biol, 36:85-95

RIBEIRO,J.S.B. 1985a. Estudos de ecologia e controle ambiental na região do reservatório da UHE de Balbina. Sub projeto Limnologia e Macrófitas aquáticas. Relatório técnico, Janeiro a Junho/85 Convênio ELN/CNPq/INPA, Manaus, $49 \mathrm{p}$

RIBEIRO,J.S.B. 1985b. Estudos de ecologia e controle ambiental na região do reservatório da UHE de Balbina. Sub projeto Limnologia e Macrófitas aquáticas. Relatório técnico, Julho a Dezembro/85. Convênio ELN/CNPq/ INPA, Manaus, 73p.

SANTOS,G.M. 1980. Aspectos de sistemática e morfologia de Schizodon fascatus Agassiz, 1829, Rhytiodus microlepis Kner, 1859 e $R$. argenteofuscus Kner, 1859 (Characoidei) do lago Janauacá, AM. Acta Amazonica, 10 (3): 635-649.

SANTOS,G.M. 1981. Estudos da alimentação e hábitos alimentares de Schizodon fasciatus, Rhytiodus microlepis e R. argenteofuscus do lago Janauacá,AM. (Osteichthyes, Characoidei, Anostomidae). Acta Amazonica, 11 (2): 267-283.

SANTOS,G.M.1982. Caracterização, hábitos alimentares e reprodutivos de quatro espécies de "aracus" e considerações sobre o grupo no lago Janauacá, AM. (Characoidei). Acta Amazonica, 12 (4): 713-739.
SANTOS,G.M. 1991. Pesca e ecologia dos peixes de Rondônia. Tese de Doutorado, INPA/FUA. Manaus,AM. 213p.

SANTOS,G.M. 1995. Impactos da hirelétrica Samuel sobre as comunidades de peixes do rio Jamari (Rondônia, Brasil). Acta Amazonica, 25 (3/4): 247-280.

SANTOS,G.M.; JEGU,M.; MERONA,B. 1984. Catálogo dos peixes comerciais do baixo Tocantins. Manaus, Projeto Tucuruí. Eletronorte/INPA. 83p.

SANTOS,G.M. ; JEGU, M. 1987. Novas ocorrências de Gnathodolus bidens, Synaptolaemus cingulatus e descrição de duas espécie novas de Sartor (Characiformes, Anostomidae). Amazoniana, 10 (2): 181-196.

SANTOS,G.M.; JEGU,M. 1989. Inventário taxonômico e redescriçăo das espécies de anostomídeos (Characiformes, Anostomidae) do baixo rio Tocantins, PA. Brasil. Acta Amazonica, 19: 159-213.

SANTOS,G.M.; ROSA,P.S. (No prelo) Alimentação de Anostomus ternetzi e Synaptolaemus cingulatus, duas espécies de peixes amazônicos com boca superior. Rev. Bras. Biol.

SIOLI,H. 1968. Hidrochemistry and geology in the Brazilian Amazon Region. Amazoniana, 1 (3): 267-277.

STEINDACHNER,F. 1876. Ichthyologische Beitraege. V. Sitzs. Akad. Wiss. Wien, 74: 49-240.

WINTERBOTTOM,R. 1980. Systematics, osteology and phylogenetic relationships of fishes of the Ostariophysan Subfamily Anostomidae (Characoidei, Anostomidae). Life Sciences Contributions 123, Royal Ontario Museum. 112 p. 


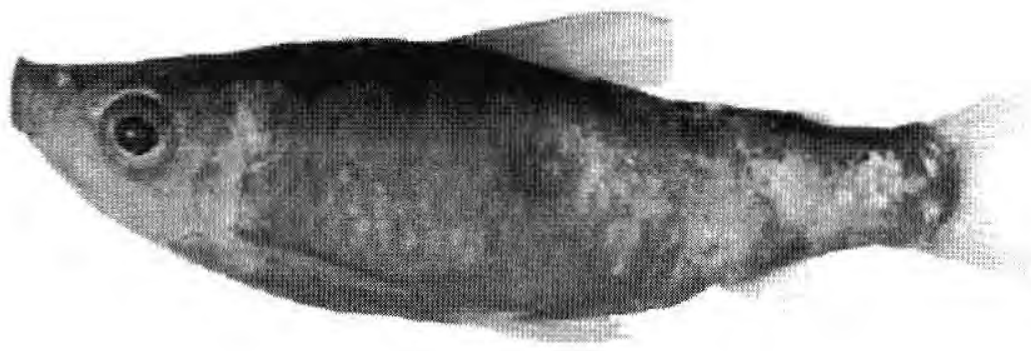

Fig. 3. Gnathodolus bidens. INPA 10164, 111, 2mm CP

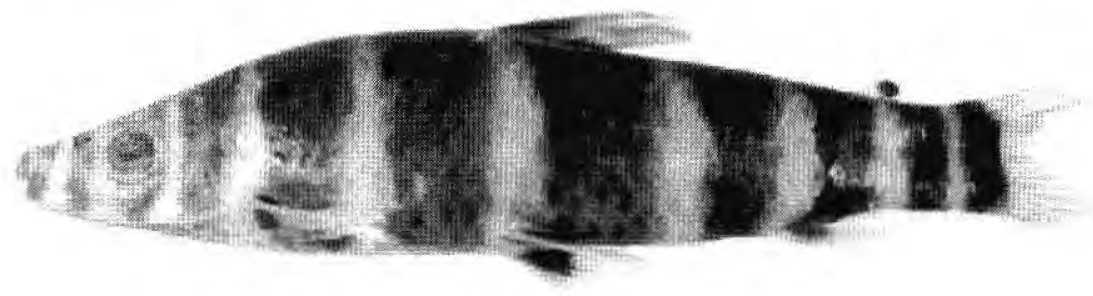

Fig. 4. Synaptolaemus cingulatus. INPA 10047, $92 \mathrm{~mm} \mathrm{CP}$

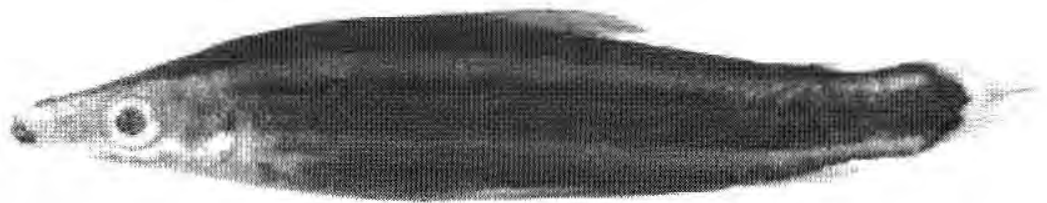

Fig. 5. Anostomus ternetzi. INPA 10006, 70,7mm CP

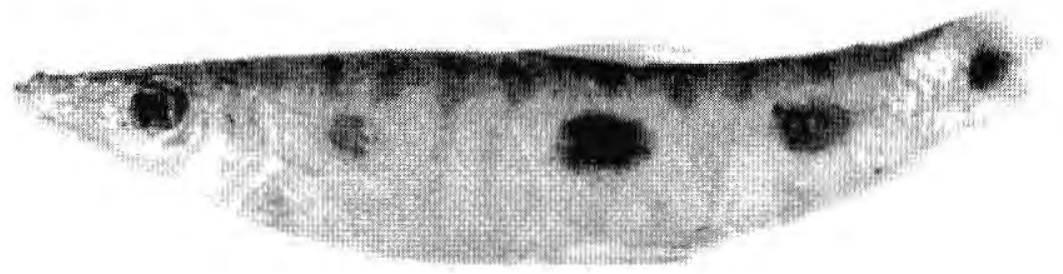

Fig. 6. Anostomus plicatus. INPA $10008,65 \mathrm{~mm}$ CP

Figuras 3 a 31. Ilustração das espécies de Anostomideos da bacia do rio Uatumà tratadas no presente estudo. 


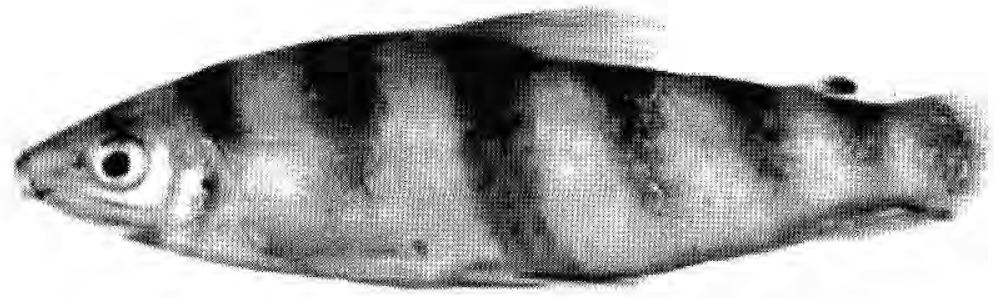

Fig, 15. Leporinus desmotes INPA $10066,118 \mathrm{~mm} \mathrm{CP}$



Fig. 16. Leoporinus desmotes, juvenil. INPA 10134, 26mm CP

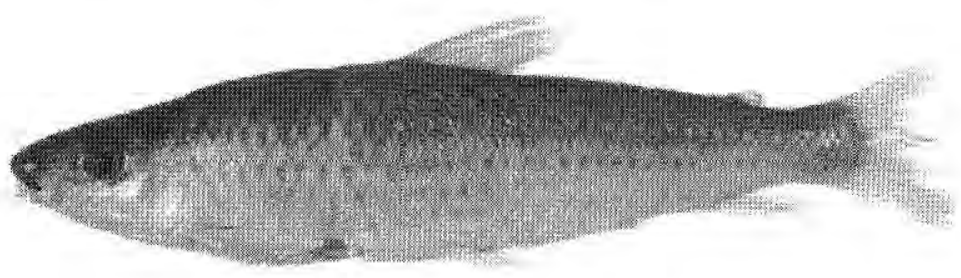

Fig. 17. Leporinus brunneus. INPA 10069, 209.8mm CP

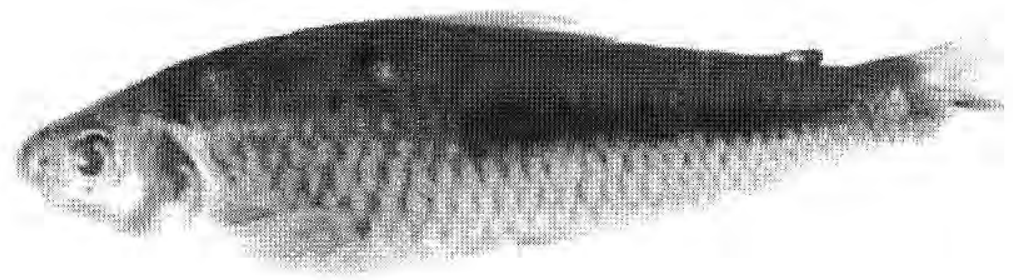

Fig, 18. Leporinus agassizi. INPA $10114,259 \mathrm{~mm}$ CP 


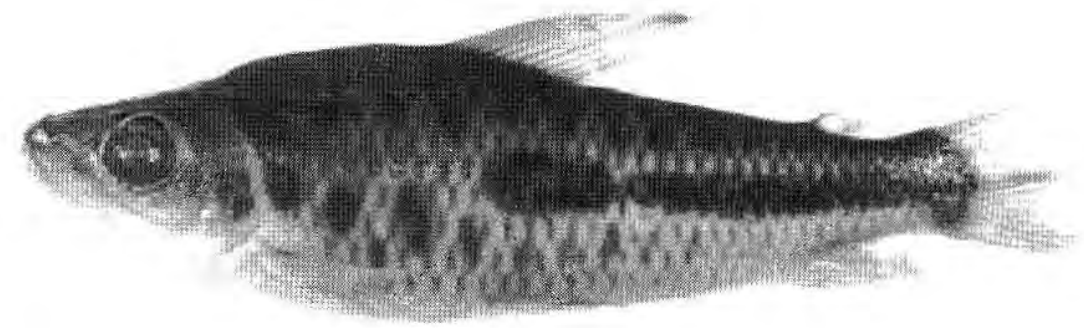

Fig. 19. Leporinus agassizi, juvenil. INPA $10111,79 \mathrm{~mm}$ CP

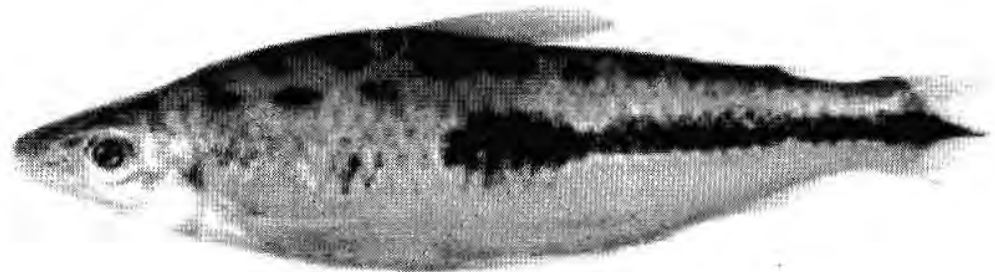

Fig. 20. Leporinus uatumaensis sp.n. INPA $10087,89 \mathrm{~mm}$ CP

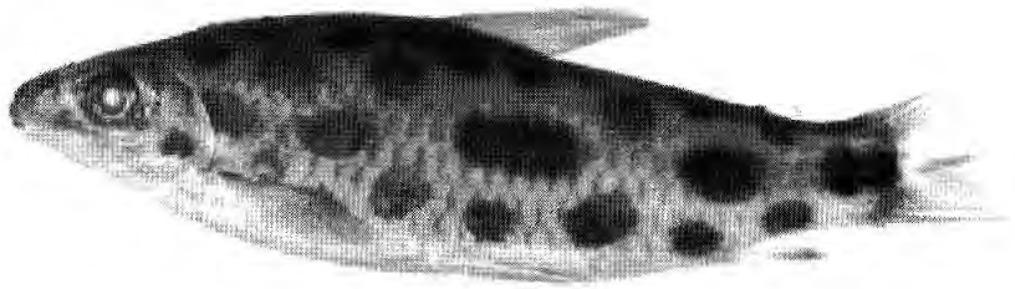

Fig. 21. Leporinus megalepis. INPA 10041, 80mm CP

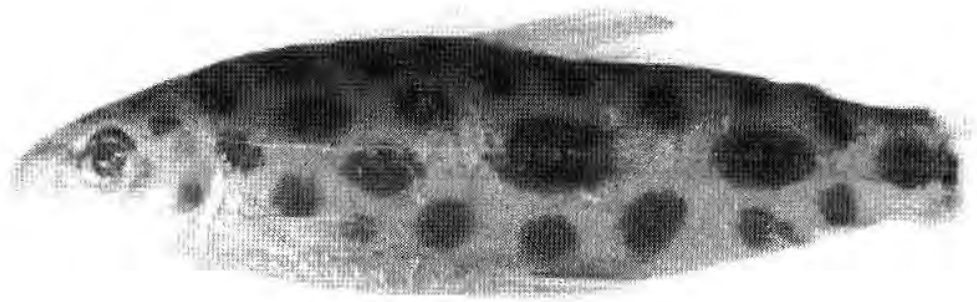

Fig. 22. Leporinus megalepis, juvenil. INPA 10136, 42mm CP 


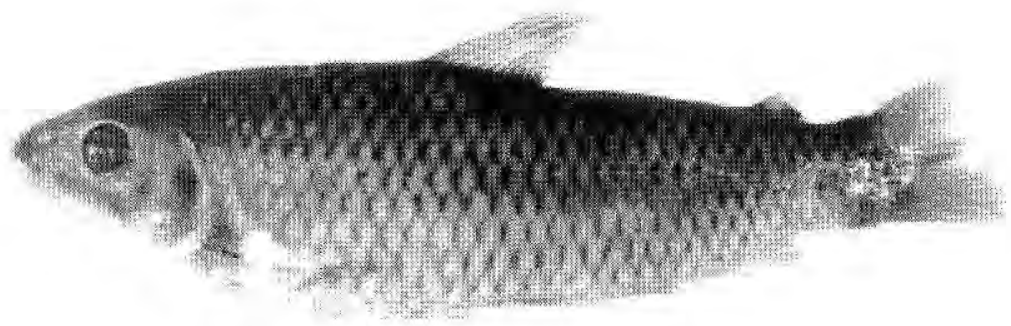

Fig. 23. Leporinus granti. INPA 10098, 152mm CP

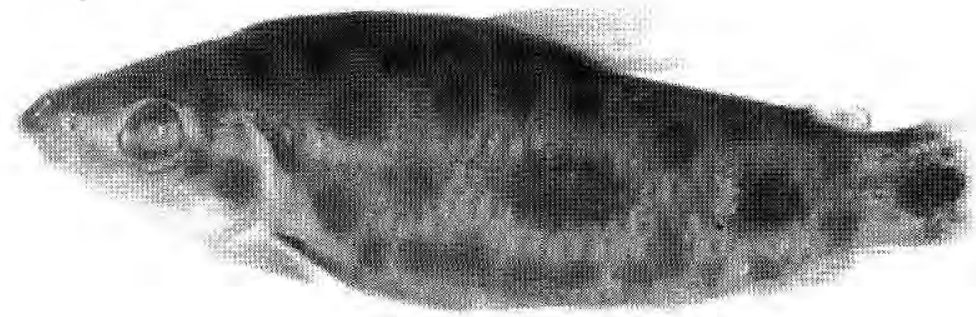

Fig. 24. Leporinus granti, juvenil. INPA $10115,55 \mathrm{~mm}$ CP

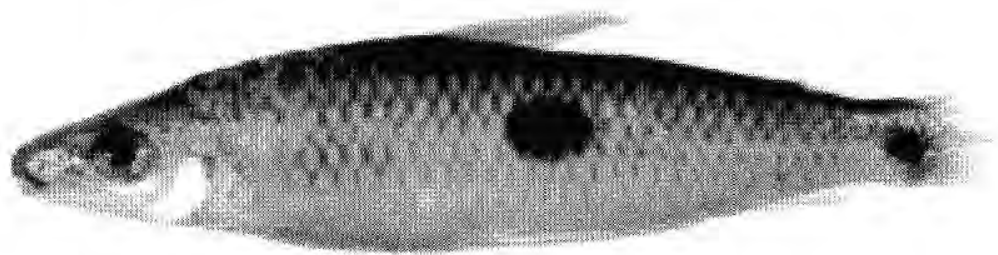

Fig. 25. Leporinus aripuanaensis. INPA 10043, 92mm CP

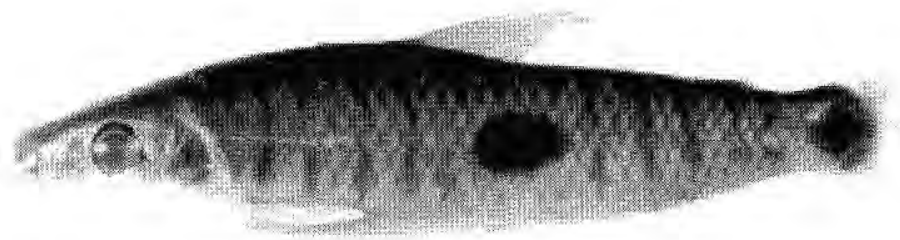

Fig. 26. Leporinus aripuanaensis, juvenil. INPA 10045, 58,7mm 


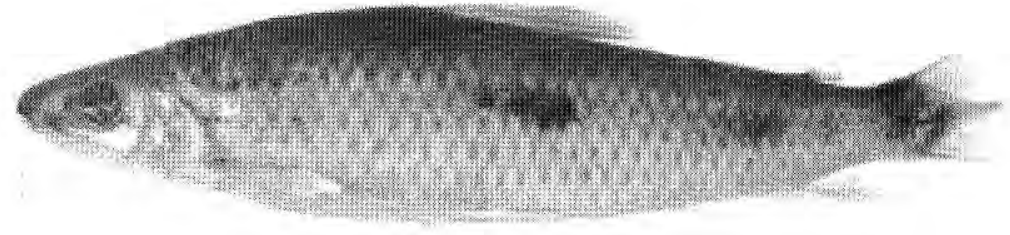

Fig. 27. Lepormus cylindriformes. INPA 10070, 176mm CP



Fig. 28. Leporinus cylindriformes, juvenil. INPA 10133, 50mm CP

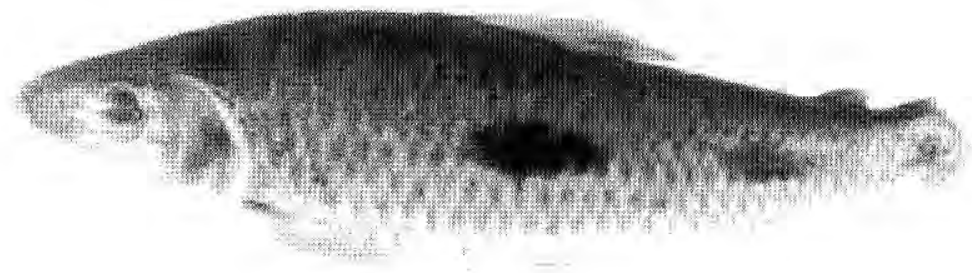

Fig. 29. Leporinus friderici, INPA $10115,218 \mathrm{~mm} \mathrm{CP}$

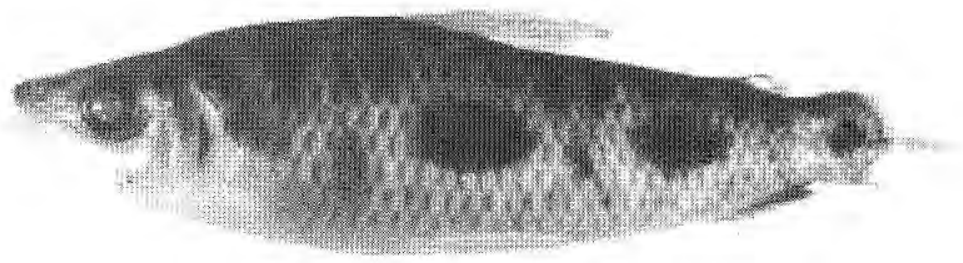

Fig. 30. Leporinus friderirt, juvenil. INPA 10132, $68 \mathrm{~mm}$ CP 




Fig. 31. Leporimus pitingai sp.n. INPA J0J 26, $285 \mathrm{~mm}$ CP 